This document is the accepted manuscript version of the following article:

Hu, Z., Wyrzykowski, M., \& Lura, P. (2020). Estimation of reaction kinetics of geopolymers at early ages. Cement and Concrete Research, 129, 105971 (12 pp.). https://doi .org/10.1016/j.cemconres.2020.105971

This manuscript version is made available under the CC-BY-NC-ND 4.0

1icense http://creativecommons.org/1icenses/by-nc-nd/4.0/

Hu, Z., Wyrzykowski, M. and Lura, P., 2020. Estimation of reaction kinetics of geopolymers at early ages. Cement and Concrete Research, 129, p.105971.

\title{
Estimation of reaction kinetics of geopolymers at early ages
}

\author{
Zhangli $\mathrm{Hu}^{1 *}$, Mateusz Wyrzykowski ${ }^{1}$, Pietro Lura ${ }^{1,2}$ \\ ${ }^{1}$ Empa, Swiss Federal Laboratories for Materials Science and Technology, Dübendorf CH-8600, Switzerland \\ ${ }^{2}$ Institute for Building Materials, ETH Zurich, Zurich CH-8092, Switzerland
}

\begin{abstract}
The degree of reaction and the reaction kinetics of the reactants in geopolymers correlate closely to their mechanical properties and their durability. However, quantifying the reaction using conventional methods is challenging, especially for alkali activated siliceous fly ash with low reactivity.

In the present study, a novel method to estimate the reaction kinetics of geopolymers at early ages based on the evolution of the internal relative humidity is proposed. The experimental results show increasing internal relative humidity of the two studied fly-ash based geopolymers with increasing hydration time. The internal relative humidity increases due to the reduction of the ion concentration in the pore solution as they become consumed during the reaction of the fly ash. Verified by comparison with compressive strength, heat release in isothermal calorimetry and degree of reaction measured with selective dissolution, this new method is useful to estimate the reaction kinetics of geopolymers having limited self-desiccation.
\end{abstract}

Keywords: internal relative humidity; reaction kinetics; fly-ash based geopolymers; early age concrete

\section{Introduction}

Alkali-activated materials (AAM) are one type of alternative cementitious materials. Often, industrial byproducts are used as precursors for the reaction with alkali activators, e.g. fly ash, slag and red mud $[1,2]$. AAM using aluminosilicate precursors, e.g. fly ash, metakaolin and calcined clay, are categorized as geopolymers [3]. Widening the usage of AAM would benefit the sustainability of the construction field in terms of reducing the global carbon dioxide emissions during the production of ordinary Portland cement.

Large amounts of fly ash of different composition and quality are available worldwide as a byproduct from coal burning. While fly ash is widely employed as supplementary cementitious material, due to its comparatively low reactivity and composition that changes in time even within the same plant, its degree of utilization in some countries is low compared e.g. with blast-furnace slag and silica fume [4].Besides its main use in the construction industry in blends with Portland cement, fly ash can be introduced in fly-ash based geopolymers [1,2]. Activated with strongly alkaline solutions, based on sodium hydroxide, sodium silicate solution or their blends, the Si-O and the Al-O in fly ash dissolve and react with the alkaline solutions to form amorphous aluminosilicate gel [1]. This main reaction product is principally a 3D network of $\mathrm{SiO}_{4}$ and $\mathrm{AlO}_{4}$ tetrahedra [5]. The reactivity of fly ash in geopolymers provides a criterion to select fly ash with potential in practical applications, to predict strength development and, in research, to support microstructural simulations. However, this type of quantification for siliceous fly-ash based

\footnotetext{
${ }^{1}$ Corresponding author: zhangli.hu@empa.ch, Tel +41-587656575, Fax 0587656935
} 
geopolymers is a challenging task, especially at early ages. In fact, the low reactivity of siliceous fly ash hinders the precise quantification of the degree of reaction.

Scrivener et al. reviewed commonly-used methods for determining the degree of reaction of fly ash in cementitious blended systems [6]. In general, these methods can also be applied in AAM. However, the application is not straightforward for fly-ash based geopolymers. For instance, due to the large amount of amorphous phases existing in fly ash, X-ray diffraction (which quantifies the amount of crystalline phases) is not preferred for fly-ash based geopolymers unless sophisticated (and possibly error-prone) approaches are used in the analysis [7]. In the literature, a few conventional methods have been proposed. A widely used direct method is called selective dissolution or selective chemical attack. Fernández-Jiménez et al. [8] used 1:20 hydrochloric acid $(\mathrm{HCl})$ solution prepared from a 37\% $\mathrm{HCl}$ solution and water to dissolve hydrated fly-ash based geopolymers. Researchers also used other types of solutions in the literature, such as based on picric acid [9] or $1: 9 \mathrm{HCl}$ and $5 \% \mathrm{Na}_{2} \mathrm{CO}_{3}$ [10]. However, this method has three main drawbacks: a) different types of fly ash may require different types of acids; b) the method requires crushing and grinding the hydrated materials to a predetermined fineness and the selection of this fineness affects the amount of insoluble residue; c) the accuracy control is difficult and is highly reliant on the operator. In addition, the use of strong acids is potentially harmful. Another method reported in the literature is based on deconvolution of the ${ }^{29} \mathrm{Si}$ nuclear magnetic resonance (NMR) spectra of fly-ash based geopolymers. Lee and Lee [11] used this method to determine the reactivity of slag and fly ash independently in slag-fly ash combined AAM. With ${ }^{29} \mathrm{Si}$ NMR, the accuracy of the determination depends on a deconvolution of the spectra, which requires considerable experience. Besides, the high content of iron, a paramagnetic impurity, in fly ash can hamper NMR measurements [12].

Since the above-mentioned methods are discontinuous, insufficient data points may not allow estimating the reaction kinetics precisely, especially in explorative studies where the kinetics is unknown. For determining the reaction kinetics continuously, isothermal calorimetry, which measures the heat release during the reaction, is one of the preferred methods [2,7]. Yet, one needs to be aware that for alkaliactivated siliceous fly-ash systems at low temperatures, the heat release after the initial peak may be very low, which results in low signal-to-noise ratio. Provis et al. [13] used in-situ energy dispersive X-ray diffractometry as an alternative method to quantify the reaction kinetics. They also proposed a mathematical model for predicting the reaction kinetic of geopolymers [14]. This model combined a multi-step reaction process and silicate species determination using high resolution ${ }^{29} \mathrm{Si} \mathrm{NMR}$. According to the authors [14], this model agreed well with in-situ energy dispersive X-ray diffractometry results in [13].

Along with the reaction, the internal relative humidity $(\mathrm{RH})$ evolves in the systems. In Portland cements, the mechanisms associated with the change (reduction) of internal RH have been clarified: self-desiccation resulting from water consumption by cement hydration (chemical shrinkage) and presence of ions in the pore solution [15]. In AAM, the evolution of the internal RH during the reaction of the system may differ from that in Portland cement. Contradictory trends were reported in fly-ash based geopolymers: the RH either increased or decreased with the reaction time [16,17]. The exact mechanisms involved are also unclear.

In this study, the internal RH of fly-ash based geopolymers was investigated. The geopolymers were prepared with siliceous fly ash, activated by either solely sodium hydroxide solution $(\mathrm{NaOH})$ or blends of sodium silicate solution and $\mathrm{NaOH}$ solution and cured at 20,30 and $40{ }^{\circ} \mathrm{C}$. A new method to estimate the reaction kinetics continuously based on the internal $\mathrm{RH}$ evolution is proposed. Independent measurements 
of compressive strength, isothermal calorimetry and pore solution composition were used for the validation of the method.

\section{Materials and methods}

\subsection{Raw materials and mixtures}

A siliceous fly ash (labeled as FA) was used in the mixtures as a precursor. The oxides composition of the fly ash determined by X-ray fluorescence (XRF) is shown in Table 1. The mineral composition was measured with X-ray diffraction (PANalytical X'pert Pro, CoK $\alpha$ radiation, $45 \mathrm{kV}, 40 \mathrm{~mA}$ ) and quantified using X'Pert HighScore Plus software V.4.8, see Table 2. 20 mass- $\%$ of $\mathrm{CaF}_{2}$ were added as an internal standard to determine the amorphous content. The geopolymers were prepared with a mixture of commercial sodium silicate solution (waterglass) and $\mathrm{NaOH}$ (labelled as -NS) or with solely $\mathrm{NaOH}$ solution (labelled as - $\mathrm{NH}$ ). The waterglass had an initial solid content of $35 \%$. The $\mathrm{Na}_{2} \mathrm{O} / \mathrm{SiO}_{2}$ in the waterglass- $\mathrm{NaOH}$ solution was 2.0. The concentration of the pure $\mathrm{NaOH}$ solution was $6.4 \mathrm{M}$, prepared with $\mathrm{NaOH}$ pellets and ultrapure water. The detailed mix design for the two systems is given in Table 3 . The pastes were mixed using a vacuum mixer for $2 \mathrm{~min}$ with a speed of $450 \mathrm{rpm}$. After mixing, specimens for compressive strength, pore solution extraction and selective dissolution were cured at $20 \pm 0.3{ }^{\circ} \mathrm{C}$ and $40 \pm 0.3{ }^{\circ} \mathrm{C}$ in sealed plastic vessels to avoid evaporation of water and carbonation.

Table 1. Oxide composition of the fly ash used in the study (mass \%)

\begin{tabular}{cccccccccccccc}
\hline Samples & $\mathrm{SiO}_{2}$ & $\mathrm{Al}_{2} \mathrm{O}_{3}$ & $\mathrm{Fe}_{2} \mathrm{O}_{3}$ & $\mathrm{CaO}$ & $\mathrm{MgO}$ & $\mathrm{SO}_{3}$ & $\mathrm{Na}_{2} \mathrm{O}$ & $\mathrm{K}_{2} \mathrm{O}$ & $\mathrm{TiO}_{2}$ & $\mathrm{P}_{2} \mathrm{O}_{5}$ & $\mathrm{Mn}_{2} \mathrm{O}_{3}$ & $\mathrm{Cr}_{2} \mathrm{O}_{3}$ & LOI. \\
\hline $\mathrm{FA}$ & 53.52 & 21.94 & 8.32 & 5.56 & 2.46 & 0.46 & 0.95 & 2.15 & 0.96 & 0.66 & 0.08 & 0.02 & 2.35 \\
\hline
\end{tabular}

Table 2. Mineral composition of the fly ash used in the study (mass \%)

\begin{tabular}{cccccccccc}
\hline Samples & Mullite & Quartz & Magnetite & Hematite & Periclase & Anhydrite & Lime & Calcite & Amorphous \\
\hline FA & 12.7 & 9.6 & 1.3 & 0.7 & 0.5 & 0.3 & 0.3 & 0.1 & 74.6 \\
\hline
\end{tabular}

Table 3. Mix proportions of the fly ash pastes (g)

\begin{tabular}{ccccccc}
\hline Mix & FA & NaOH pellets & waterglass & water & $\begin{array}{c}\text { water to binder } \\
\text { ratio }\end{array}$ & $\begin{array}{c}\text { liquid to binder } \\
\text { ratio }\end{array}$ \\
\hline FA-NS & 100.0 & 5.9 & 16.5 & 28.5 & 0.39 & 0.45 \\
FA-NH & 100.0 & 10 & - & 38.8 & 0.39 & 0.39 \\
\hline
\end{tabular}

\subsection{Internal relative humidity}

The internal RH of the two geopolymers was continuously measured with water activity sensors (HC2$\mathrm{AW}$, Rotronic) at 20,30 and $40{ }^{\circ} \mathrm{C}$ for 7 days. The temperature of the sensors and the samples was controlled within $\pm 0.1{ }^{\circ} \mathrm{C}$ by an external water bath with water circulating in the casings of the measuring stations. The sensors together with the sample holder were located in a covered box in a temperature and RH controlled room. Before each measurement, the sensors were dried above silica-gel. The sensors were calibrated at the beginning and at the end of the measurements using saturated salt solutions: $\mathrm{NaCl}, \mathrm{KCl}$, $\mathrm{KNO}_{3}$ and $\mathrm{K}_{2} \mathrm{SO}_{4}$. The equilibrium relative humidities of the four saturated salt solutions at 20,30 and $40{ }^{\circ} \mathrm{C}$ are listed in Table 4. The actual measurements were performed at each temperature right after the 
pre-calibration. Freshly mixed pastes were poured into cylindrical plastic containers (Ø43mm $\times 12 \mathrm{~mm})$ and were inserted immediately in sealed measuring chambers. The data were recorded every minute. The RH of the two alkali activators and of the extracted pore solution of the different specimens (see Section 2.5) at different temperatures was also measured. The pore solution of the different specimens cured at both 20 and $40{ }^{\circ} \mathrm{C}$ at different ages were extracted with a hydraulic piston. The pore solutions were placed in the same plastic cylindrical container, inserted into the sample holder and measured exactly as the pastes. The averaged time required for reaching the equilibrium $\mathrm{RH}$ of the measured pore solution was shorter than 1 $\mathrm{h}$, see appendix A.

Table 4. Equilibrium relative humidity of the saturated salt solutions used for calibration [18]

\begin{tabular}{ccccc}
\hline Temperature & $\mathrm{NaCl}$ & $\mathrm{KCl}$ & $\mathrm{KNO}_{3}$ & $\mathrm{~K}_{2} \mathrm{SO}_{4}$ \\
\hline $20^{\circ} \mathrm{C}$ & $75.5 \%$ & $85.1 \%$ & $94.6 \%$ & $97.6 \%$ \\
$30{ }^{\circ} \mathrm{C}$ & $75.1 \%$ & $83.6 \%$ & $92.3 \%$ & $97.0 \%$ \\
$40{ }^{\circ} \mathrm{C}$ & $74.7 \%$ & $82.3 \%$ & $89.0 \%$ & $96.4 \%$ \\
\hline
\end{tabular}

\subsection{Compressive strength}

The compressive strength development of the two geopolymers at 20 and $40{ }^{\circ} \mathrm{C}$ was measured to correlate it with the degree of reaction of the geopolymers. The dimensions of the specimens used in the compressive strength tests were $20 \times 20 \times 100 \mathrm{~mm}^{3}$. The specimens were cast in rubber molds, sealed with parafilm and stored either in an oven at $40 \pm 0.3{ }^{\circ} \mathrm{C}$ or in a room with controlled temperature of $20 \pm$ $0.3{ }^{\circ} \mathrm{C}$ until the specific measurement ages. The specimens were first broken in two in 3-point bending tests and then the two resulting pieces from one specimen were used for the compressive strength tests. The loading machine used for both tests was manufactured by Walter+Bai AG (Model Digicon 2000) and the loading rate was $20 \mathrm{~N} / \mathrm{s}$. Duplicate specimens for each mixture at each age were tested and the mean values and the standard deviations are reported.

\subsection{Isothermal calorimetry}

A TAM air isothermal calorimeter was used to measure the heat flux of the two systems. The measurements were performed at 20,30 and $40{ }^{\circ} \mathrm{C}$. Approximately $5 \mathrm{~g}$ of fly ash powders were weighed and filled in glass ampules. For all temperatures, internal mixing using Admix ampoules was employed to avoid artifacts due to temperature equilibration after external mixing [19]. The reported results were normalized by the mass of fly ash in each specimen.

\subsection{Pore solution extraction and ion chromatography}

The pore solution of the two mixtures with FA at different ages was extracted with a hydraulic press [20]. The RH of the extracted pore solution was measured with the water activity sensors as described in Section 2.2. The ion concentrations of the extracted pore solutions were measured with ion chromatography (IC) at chosen ages of 7 and $12 \mathrm{~h}$ and 1, 3, 5 and 7 days. Directly after the extraction, the pore solution was filtered with a $0.45 \mu \mathrm{m}$ nylon filter. The solutions were then diluted to $\times 10, \times 100$ and $\times 1000$ with ultrapure water to avoid precipitation. The concentrations of $\mathrm{Ca}, \mathrm{Al}, \mathrm{K}, \mathrm{Na}, \mathrm{Mg}$, and $\mathrm{Si}$ were measured. The $\mathrm{pH}$ was measured with a $\mathrm{pH}$ meter (Meter 766) calibrated with five $\mathrm{NaOH}$ solutions with different concentrations $(0.01,0.1,0.2,0.5$ and $1.0 \mathrm{M})$. The concentration of $\mathrm{OH}^{-}$was calculated using the measured $\mathrm{pH}$ values of the undiluted solutions considering also the ionic strength [21].

\subsection{Selective dissolution}


The selective dissolution used in this study was adapted from the procedure described in [8]. The 1:20 $\mathrm{HCl}$ water solution was applied to dissolve the raw fly ash powders and hydrated samples. The degrees of dissolution of raw fly ash and the two fly-ash based geopolymers were quantified. The hydrated samples and the raw fly ash powders were first ground in agate mortars. Powders with size smaller than $63 \mu \mathrm{m}$ were collected and dried in an oven at $110{ }^{\circ} \mathrm{C}$ for 3 hours. About $1 \mathrm{~g}$ of dried powders (the exact weight was recorded) were added to a solution with $14.45 \mathrm{ml} 32 \% \mathrm{HCl}$ and $250 \mathrm{ml}$ ultrapure water. The suspension was mixed with a mechanical mixer with mixing speed of $500 \mathrm{rpm}$ for $3 \mathrm{~h}$. Glass fiber filters (grade $\mathrm{GF} / \mathrm{C}, 1.2 \mu \mathrm{m}$ ) with diameters of $90 \mathrm{~mm}$ were used for filtration, since they are less hydrophilic compared with filter papers. The glass fiber filters were dried in the same oven for $3 \mathrm{~h}$ before filtration. The residue was washed with ultrapure water until the $\mathrm{pH}$ of the filtrate was close to 7 . The residue and the glass fiber filter were then oven-dried at $110^{\circ} \mathrm{C}$ until stable mass. The degree of reaction $\left(R_{f}\right)$ was calculated with the following equation:

$$
R_{f}=\frac{m_{d}+m_{g}-m_{r}}{m_{d}}
$$

in which $m_{d}, m_{g}$ and $m_{r}$ are the masses of dried hydrated powders, glass fiber filters and residue with the glass fiber filter together, respectively.

Considering that unreacted fly ash may partially dissolve in the acid solution, Eq.(2) needs to be used instead of Eq.(1), in which $R_{\text {raw }}$ is the degree of dissolution of unreacted fly ash which was measured beforehand:

$$
R_{f}=\frac{m_{d}-\left(m_{r}-m_{g}\right) /\left(1-R_{r a w}\right)}{m_{d}}
$$

\subsection{Thermodynamic model}

Thermodynamic modelling is essential for describing the evolution of the aqueous species in the hydrating system and hence for estimating the ionic strength and the corresponding water activity in the pore solution. The Gibbs free energy minimization computer program GEM-Selector [22,23] was used to calculate the water activity based on the aqueous species present in the pore solution of the two geopolymer systems; the concentrations of these species were measured with IC. The latest database Cemdata 18 [24] and the C-(N)A-S-Hss thermodynamic model [25] were used. The built-in extended Debye-Hückel equation in Truesdell-Jones form [26] was applied as an aqueous electrolyte function:

$$
\log _{10} \gamma_{j}=\frac{-A_{\gamma} z_{j}^{2} \sqrt{I}}{1+\dot{a} B_{\gamma} \sqrt{I}}+b_{\gamma} I+\log _{10} \frac{x_{j w}}{X_{w}}
$$

in which $\gamma$ and $z$ are the activity coefficient and formula charge, respectively. The subscript $j$ represents the $j_{\text {th }}$ species in solution. $A_{\gamma}$ and $B_{\gamma}$ are electrostatic parameters depending on temperature and pressure. $I$ is the ionic strength. $\dot{a}$ is an average distance of approach of two ions of opposite charge. $b_{\gamma}$ is a semiempirical coefficient, individual for a given electrolyte ion. $x_{j w}$ and $X_{w}$ are the molar quantity of water and the total molar amount of the aqueous phase, respectively. Parameters for a $\mathrm{NaOH}$-dominated solution were applied. Eq.(3) takes short-range interactions into account in the simulation, which is applicable for solutions with ionic strength up to 1-2 molal.

\section{Experimental results}

\subsection{Internal relative humidity}


The internal RH evolution of the two geopolymers at 20,30 and $40{ }^{\circ} \mathrm{C}$ is shown in Fig.1 (continuous lines). The internal RH of the geopolymers studied here started with a low value and increased with age. This behavior is different from that of Portland cement, in which the initial RH is normally high [27]. The starting RH for NH systems and NS systems was slightly different at different temperatures: about 73 and $86 \% \mathrm{RH}$ at $20^{\circ} \mathrm{C}$, about 70 and $87 \% \mathrm{RH}$ at $30{ }^{\circ} \mathrm{C}$ and about 70 and $87 \% \mathrm{RH}$ at $40{ }^{\circ} \mathrm{C}$. These values were similar to the measured $\mathrm{RH}$ values of the pure alkali activators at the corresponding temperatures (see discrete points with error bars in Fig.1), suggesting that the initial low RH in the geopolymers is caused by the high ion concentration in the pore solution. The ion concentration is not only related to the initial alkalinity of the activator, but also to the ions dissolved from the fly ash. On the contrary, in ordinary Portland cement pastes, the internal RH depression due to the ions dissolved in the pore solution may be about $2 \%[15,27]$.

Another obvious difference between the internal RH of geopolymers and ordinary Portland cement is the trend of the RH evolution. Due to self-desiccation in ordinary Portland cement pastes with low water-tocement ratio, the internal RH decreases as a function of hydration time [27], while at high water-to-cement ratio or with internal curing, the $\mathrm{RH}$ remains high [28]. On the contrary, at all testing temperatures, the $\mathrm{RH}$ of the two geopolymers in this study increased during the first week, as evident from Fig.1. The RH increase phenomenon had been previously observed in fly-ash based geopolymers cured at $40{ }^{\circ} \mathrm{C}$ [17] and in fly ash-slag based geopolymers cured at $20{ }^{\circ} \mathrm{C}$ [16], both activated with mixed solutions of $\mathrm{NaOH}$ and waterglass. In the fly ash-slag based geopolymers [16], the internal RH increased to a maximum RH rapidly and remained at that high $\mathrm{RH}$ level. In [17], it can be supposed that condensation may have occurred during the measurements, leading to RH of $100 \%$ after about 2 days of reaction. Ma [17] formulated two hypotheses to explain the observed RH increase in fly-ash based geopolymers, albeit without providing further supporting evidence: 1) delayed moisture equilibrium between the sensors and the specimen; 2) consumption of sodium and silicate species in the alkaline solution due to the reaction of fly ash. Based on the new evidence gathered in the present study, however, the mechanism according to the hypothesis 1 does not seem to play a major role, also considering the consistency between the initial $\mathrm{RH}$ of the systems and of their alkali activators. Slightly higher RH was observed in FA-NH and FA-NS at $20{ }^{\circ} \mathrm{C}$ compared to the $\mathrm{RH}$ of the alkali activators. For a detailed discussion, the reader is referred to Section 4.2 and 4.3. The RH evolution of the FA-NH system showed a faster rate of RH increase starting at about $5 \mathrm{~d}$ at $20^{\circ} \mathrm{C}, 2 \mathrm{~d}$ at $30{ }^{\circ} \mathrm{C}$ and $1 \mathrm{~d}$ and $40{ }^{\circ} \mathrm{C}$ (marked as turning point in Fig. 1).

(a)

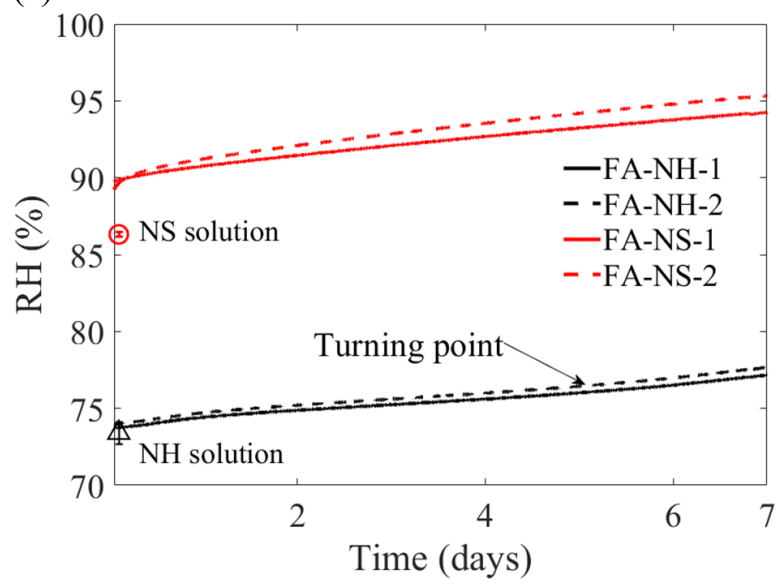

(b)

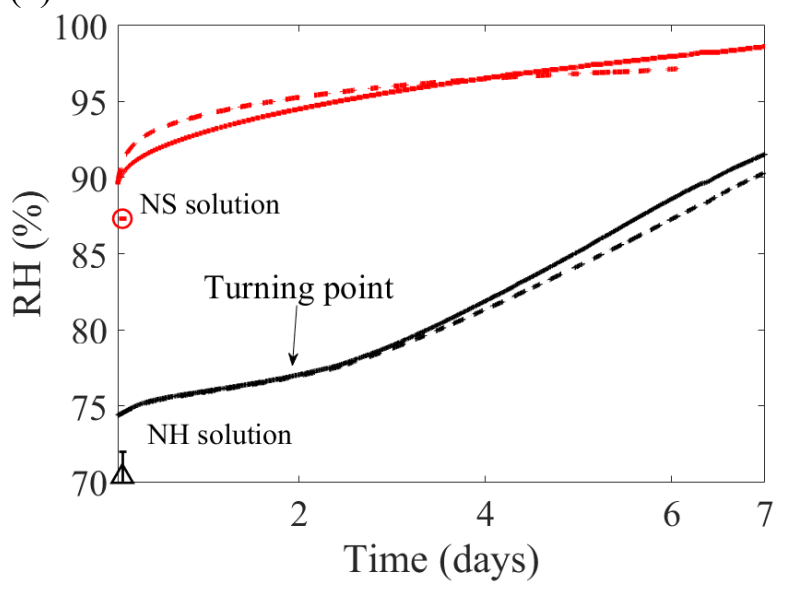




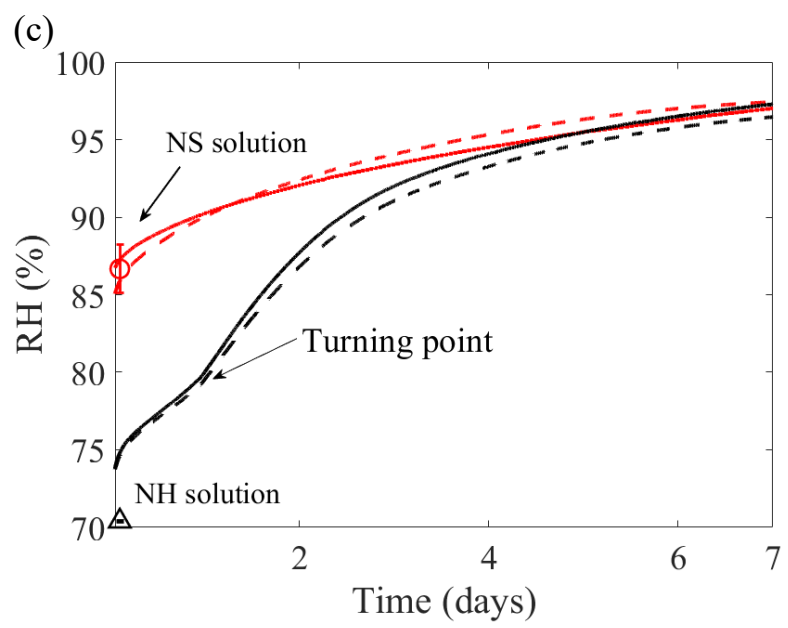

Figure 1. Internal $\mathrm{RH}$ of the two systems at different temperatures: a) at $20^{\circ} \mathrm{C}$; b) at $30^{\circ} \mathrm{C}$; c) at $40{ }^{\circ} \mathrm{C}$.

The "turning points" indicate the time when a sudden change of the $\mathrm{RH}$ increasing kinetics occurs.

\subsection{Compressive strength}

The compressive strength development of FA-NS and FA-NH at 20 and $40{ }^{\circ} \mathrm{C}$ is given in Fig.2. Increasing the curing temperature enhanced the compressive strength. FA-NS was confirmed to be more reactive, since the compressive strength was higher especially at earlier ages than that of FA-NH. At $40{ }^{\circ} \mathrm{C}$, FA-NS and FA-NH achieved similar compressive strength at $21 \mathrm{~d}$, even though the former system had higher compressive strength than the latter system before $3 \mathrm{~d}$. Higher temperature curing is necessary for obtaining fly-ash based geopolymers with reasonable compressive strength within relatively short time.

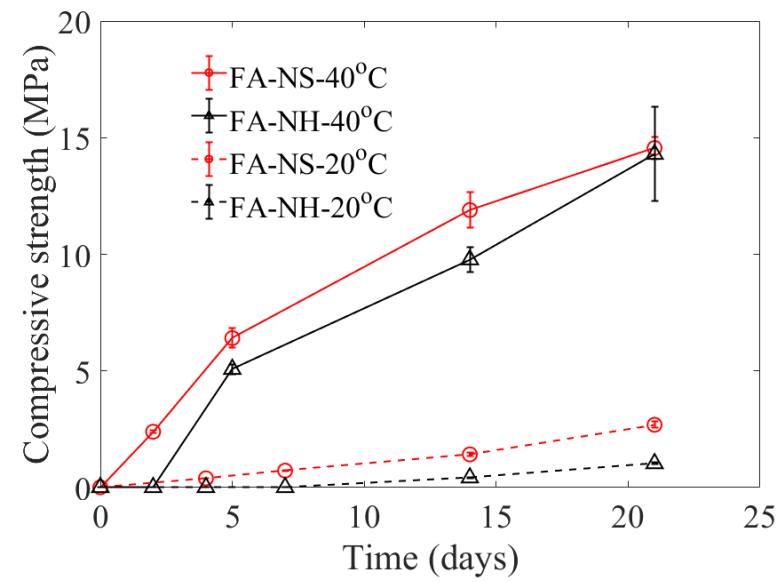

Figure 2. Compressive strength of the two systems at 20 and $40{ }^{\circ} \mathrm{C}$.

\subsection{Isothermal calorimetry}

The heat flux and the cumulative heat release of the two fly-ash based geopolymers at 20,30 and $40{ }^{\circ} \mathrm{C}$ in the first $6 \mathrm{~d}$ are shown in Fig.3. Higher cumulative heat from the geopolymers at the higher temperature was observed. At $20{ }^{\circ} \mathrm{C}$, FA-NH had slightly higher cumulative heat than FA-NS. At both 30 and $40{ }^{\circ} \mathrm{C}$, the difference was larger: FA-NH had higher heat release after certain point. Moreover, the cumulative heat of FA-NH was influenced more by the temperature increase. 
Only one single exothermic peak was observed in the FA-NS system while two peaks appeared in the FANH system at different temperatures (see Fig.3 (a), (c) and (e)). The initial heat release peak at the start of the measurements in the fly ash systems was mainly associated with the dissolution of ions from the fly ash powders to the alkali activator [29]. FA-NH then showed an induction period, which is more evident than for FA-NS. According to the literature [7], the onset and the magnitude of the main peak depends on the concentration of the alkali activator. The main exothermic peak that followed the first peak indicates the transformation and polymerization of the reaction gel [30] in the FA-NH systems. The appearance of the main peak was anticipated at higher temperature. No discrete peak was detected in FA-NS, which was probably due to the faster polymerization of the aluminosilicate gel in this system [31].

The cumulative heat release and the internal RH exhibit the same general trend. The sudden acceleration in FA-NH was also observed in the heat release. The turning point related to the second exothermic peak occurred at the same ages in the two measurements (at about $5 \mathrm{~d}, 2 \mathrm{~d}$ and $1 \mathrm{~d}$ at $20^{\circ} \mathrm{C}, 30^{\circ} \mathrm{C}$ and $40{ }^{\circ} \mathrm{C}$, respectively). However, despite the much higher cumulative heat release in FA-NH at $40{ }^{\circ} \mathrm{C}$ than in FANS, the two systems experienced similar compressive strength (Fig.2). Despite the similar microstructure generated in systems with soluble $\mathrm{SiO}_{2}$ and with $\mathrm{NaOH}$ [8], the soluble silica affected the final composition of the aluminosilicate gel. Reactions with higher $\mathrm{SiO}_{2} / \mathrm{Na}_{2} \mathrm{O}$ in the reactants resulted in reaction products with higher $\mathrm{Si} / \mathrm{Al}$ and lower $\mathrm{Na} / \mathrm{Al}[32,33]$. In terms of the polymerization degree, systems activated with waterglass showed higher polymerization degree, which can be used to explain their better mechanical properties [32].

(a)

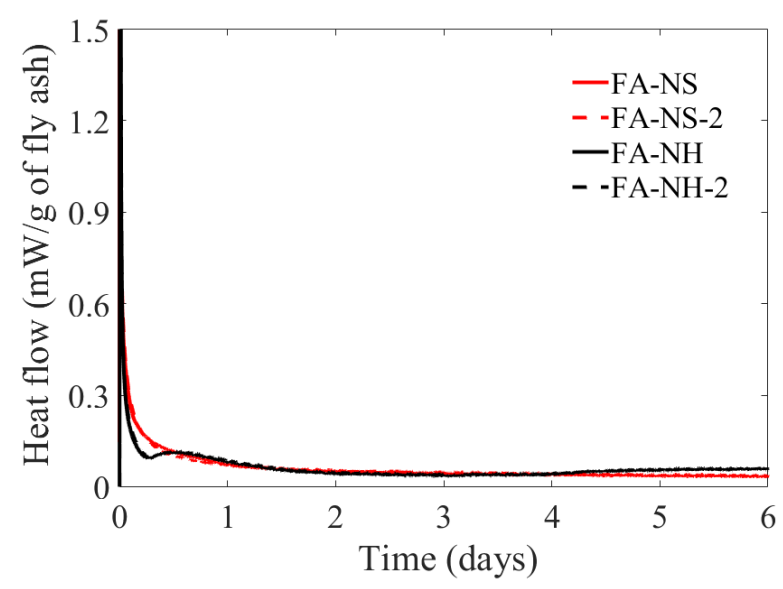

(c) (b)

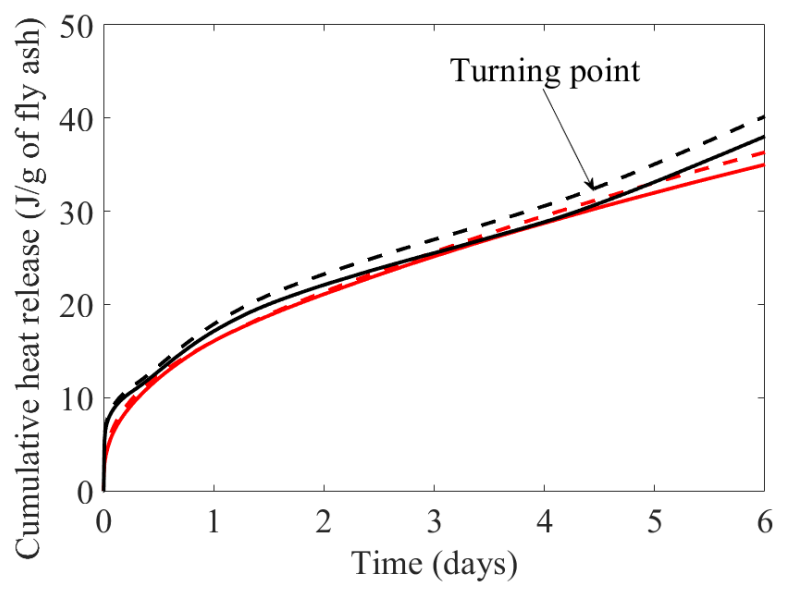

(d) 

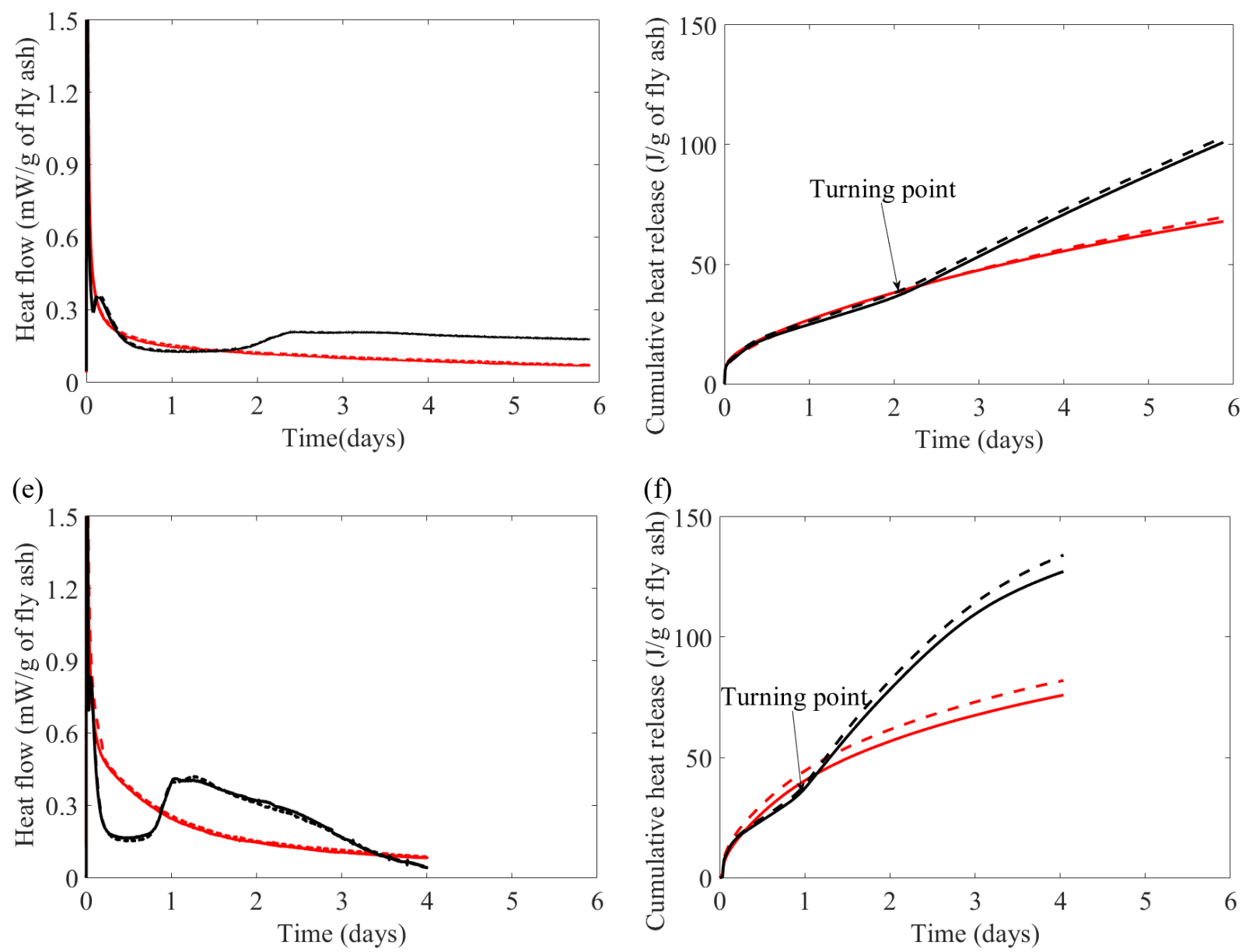

Figure 3. Heat flow and cumulative heat release (normalized to gram of fly ash in the mixture) of the two systems at the three curing temperatures: (a) and (b) at $20^{\circ} \mathrm{C}$; (c) and (d) at $30^{\circ} \mathrm{C}$; (e) and (f) at $40{ }^{\circ} \mathrm{C}$. The scale of the abscissae and the ordinates in (a) and (b) differed from the other graphs for the purpose of showing clearly the second exothermic peak and the turning point.

\subsection{Pore solution concentration}

The composition of the extracted pore solution at different ages at 20 and $40{ }^{\circ} \mathrm{C}$ was followed using IC (see Fig.4). In both systems, $\mathrm{Na}, \mathrm{Si}$ and $\mathrm{OH}^{-}$are the dominant species. The most significant concentration changes appeared for $\mathrm{Al}, \mathrm{Na}$ and $\mathrm{Si}$, especially in $\mathrm{FA}-\mathrm{NH}$ at $40{ }^{\circ} \mathrm{C}$. Higher temperature leads to faster concentration changes of the species, which agrees with [31]. Higher concentration of Al in FA-NH solution at both temperatures is observed compared with the FA-NS solution. The concentration of Al tends to decrease with the reaction time in both geopolymers. Note that the concentration of $\mathrm{Na}$ in the $\mathrm{NaOH}$ activator and in the mixed solution of $\mathrm{NaOH}$ and waterglass was $6570 \mathrm{mmol} / \mathrm{l}$ and $4560 \mathrm{mmol} / \mathrm{l}$, respectively. The concentration of $\mathrm{OH}^{-}$in the two solutions was $5980 \mathrm{mmol} / \mathrm{l}$ and $1030 \mathrm{mmol} / \mathrm{l}$, respectively. In the $\mathrm{NaOH}$ and waterglass combined solution, the concentration of $\mathrm{Si}$ was $1750 \mathrm{mmol} / \mathrm{l}$. The decrease of the concentration of $\mathrm{Na}$ and $\mathrm{OH}^{-}$due to the reaction was faster in systems at $40{ }^{\circ} \mathrm{C}$. The soluble silica in the NS systems is attributed to the higher Si concentration in the pore solution. With the reaction, a decrease of the concentration followed. In the NH systems, on the contrary, the concentration of Si increased with reaction time. These observations are in line with [31]. 
The concentration of $\mathrm{Ca}, \mathrm{K}, \mathrm{Mg}$ in the pore solution is low and the change is relatively small, see Fig.4. In systematic studies [31], higher concentration of $\mathrm{Ca}$ was observed in sodium silicate activated geopolymers and the value decreased over the reaction time.

(a)

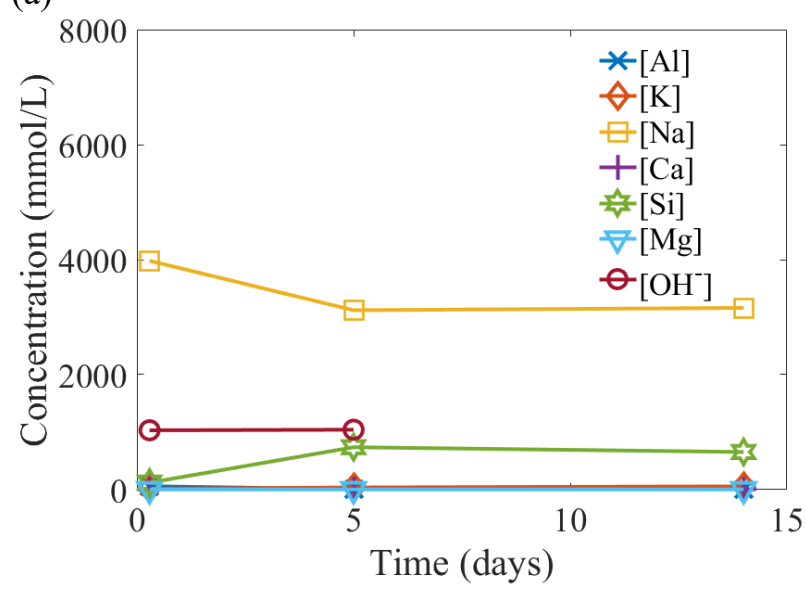

(c)

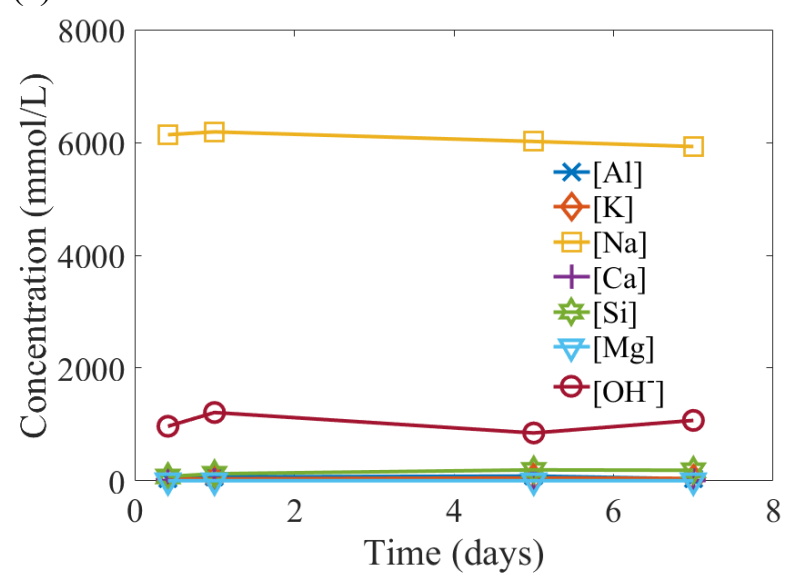

(b)

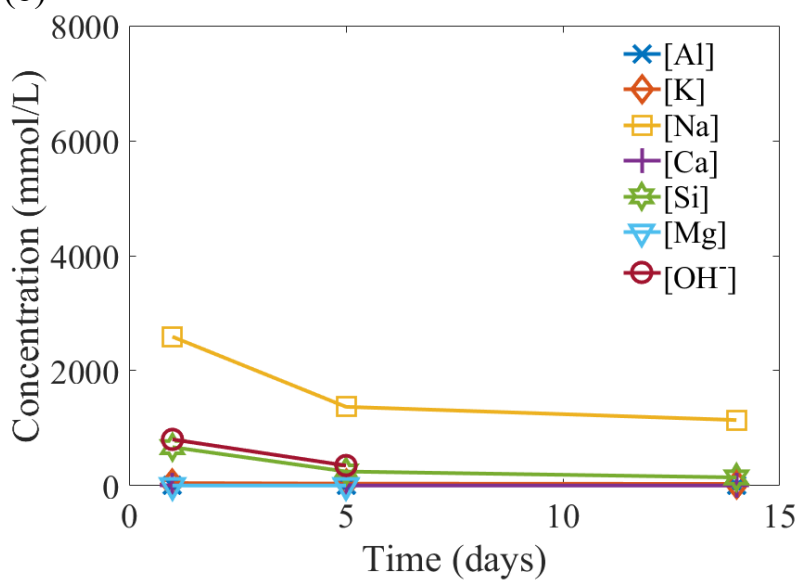

(d)

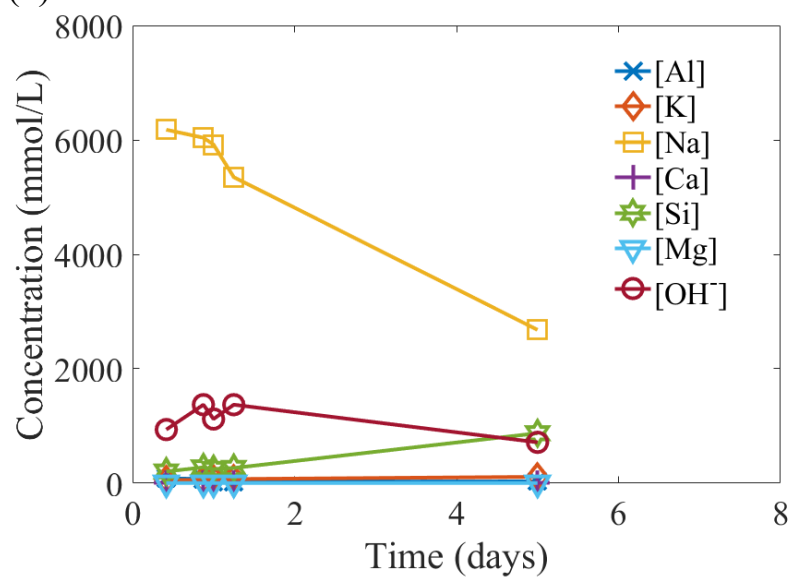

Figure 4. Pore solution concentration of FA-NS and FA-NH at different temperatures: (a) FA-NS at $20{ }^{\circ} \mathrm{C}$; (b) FA-NS at $40{ }^{\circ} \mathrm{C}$; (c) FA-NH at $20^{\circ} \mathrm{C}$; (d) FA-NH at $40{ }^{\circ} \mathrm{C}$

\section{Discussion}

\subsection{Mechanisms behind RH changes in geopolymers}

The internal RH changes in geopolymers in sealed conditions may be associated with two distinct processes: 1) pore water consumption induced by reaction of the fly ash, leading to a reduction of the internal RH, so-called self-desiccation [27,34] and 2) evolution of the ion concentration in the pore solution during the reaction process [34,35]. Water-air menisci, forming in a partially saturated porous medium, are required to trigger the first process. In addition, the emptied pores need to be small enough, at least in the hundreds of nm range, for the RH depression to be measurable. More importantly, the way water is bound in the hydration products in Portland cement and in geopolymers (based on fly ash or metakaolin) is different $[17,36,37]$. The main hydration products in Portland cement pastes, namely calcium silicate hydrates and portlandite, bind water chemically in their structure. Additionally, part of the 
water is adsorbed on the surfaces of the C-S-H gel. Both processes (chemical binding and physical adsorption) lead to a reduction of volume, referred to as the chemical shrinkage. This is responsible for emptying of pores and self-desiccation. On the other hand, in geopolymers, water is primarily bound by physical adsorption on the aluminosilicate gel $[17,37]$. This is confirmed, e.g., by the small change in the evaporable water quantity in geopolymers up to 90 days sealed cured under $40{ }^{\circ} \mathrm{C}$ [17]. In any case, physical adsorption still leads to reduction of volume in geopolymers as the physically adsorbed water occupies less space than free water. Hence, similarly as in Portland cement systems, pores are emptied, and even though due to different mechanism, this process is still referred to as chemical shrinkage. Indeed, emptying of pores in geopolymers was measured with the method designed for chemical shrinkage of Portland cement systems and was observed to reach similar magnitude as in cement pastes, e.g. about 0.05 $\mathrm{ml} / \mathrm{g}$ at about $7 \mathrm{~d}[38]$.

On the other hand, the chemical reaction occurring in geopolymers connects the Si- and Al- hydroxyl groups and releases water (see the reaction equations in Section 4.2), which results finally in an increased $\mathrm{RH}$. The overall mechanism governing RH evolution in geopolymers is thus a coupled effect of chemical shrinkage on one hand (self-desiccation), and water release on the other hand [17]. Other possible mechanisms may also be at play and further research is necessary to describe them.

The second process is active even in liquid systems. Note that precipitation of solids out of solution increases the RH, while ions that come into solution dissolved from the fly ash should decrease the RH. The starting internal RH is substantially lower than $100 \%$ due to the lower water activity of the ion-rich pore solution. With the reduction of ion concentration in the solution, its water activity increases.

To clarify the reason for the internal RH evolution in the studied systems, the comparison of the measured $\mathrm{RH}$ of the extracted pore solution and of the geopolymer pastes is shown in Fig.5. The measurements of $\mathrm{RH}$ of the solution and pastes agreed well at the specific ages. This shows that the RH in both systems is dominated by the ions in the pore solution. No significant self-desiccation occurred in both systems at both temperatures during the time period covered in this study. With prolonged reaction time, the reduction of RH due to self-desiccation can probably outweigh the increase of RH due to ions present in the solution.

The measured RH was also compared to the RH calculated with thermodynamic modelling using GEMSelector (Fig.5, solid markers), see Section 2.7. Note that the calculation is based on the aqueous species (ion concentration in the pore solution) measured with IC, see Fig.4. At $20{ }^{\circ} \mathrm{C}$, the change of the calculated RH was small during the considered ages, less than $3 \% \mathrm{RH}$ in both systems. For FA-NH, the calculated RH was slightly higher than the one measured with the RH sensor on pore solution and geopolymer pastes. Conversely, for FA-NS, the calculated RH was slightly lower than the RH from the measurements. In both cases, the difference was within $5 \% \mathrm{RH}$, which may be partly due to the errors induced by the high ionic strength (higher than the suitable range using Eq.(3) in the thermodynamic modelling). In general, at $20^{\circ} \mathrm{C}$, the increase of RH in FA-NS and FA-NH followed approximately the same kinetics and corresponded well with the evolution of the compressive strength. The same evolution can also be observed in the calorimetry results (Fig.3). At $40{ }^{\circ} \mathrm{C}$, the change of the RH was larger within the considered ages, which was consistent with the results from the measurements. The RH value from the three methods agreed reasonably well. The reason for the higher RH from the measurements on pore solution of FA-NS at $1 \mathrm{~d}$ may be due to the condensation on the sensor occurring at such high RH. It must also be remarked that despite the elaborate calibration procedure at $\mathrm{RH}$ up to $97.5 \% \mathrm{RH}$, the accuracy of the water activity sensors is better at lower RH than at high RH (see e.g. [27]). 
As indicated in Fig.4, the concentration of $\mathrm{Na}, \mathrm{Si}$ and $\mathrm{OH}^{-}$dominated the overall ion concentration in the pore solutions. When the internal RH of the pore solution was calculated with GEM-Selector, but without considering the ions dissolved from the fly ash, a difference not higher than $0.2 \% \mathrm{RH}$ was found. It can be concluded that the internal RH evolution in the fly-ash based geopolymers was mainly due to the changes of $\mathrm{Na}, \mathrm{Si}$ and $\mathrm{OH}^{-}$originally existing in the alkali activators during the reaction.

(a)

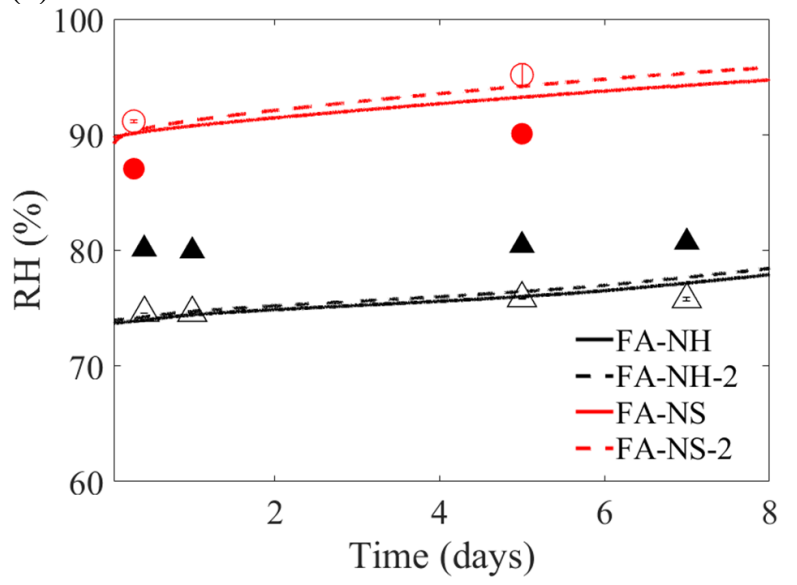

(b)

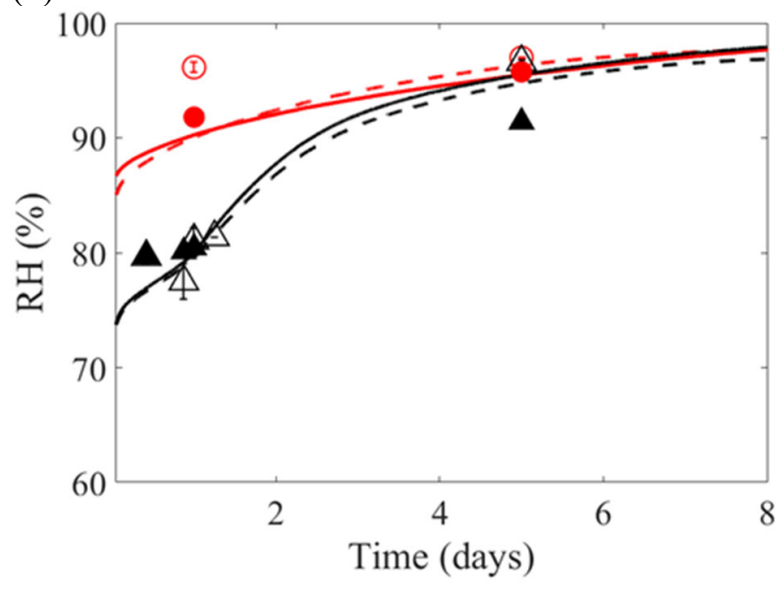

Figure 5. Comparison of the RH of the two pastes with FA (lines), RH of extracted pore solution of the two systems with FA (hollow markers, red circle for FA-NS, black triangles for FA-NH) and the RH calculated based on the ions in the solution from IC using GEM-Selector software (solid markers, red circle for FA-NS, black triangles for FA-NH): a) at $20^{\circ} \mathrm{C}$; b) at $40{ }^{\circ} \mathrm{C}$.

\subsection{Evolution of ion concentration during the reaction process of fly-ash based geopolymers}

The change in ion concentrations of the pore solution, which is mirrored in the kinetics of the $\mathrm{RH}$ evolution, is related to the different processes of the alkali activated reaction. Considering the four main steps in the reaction processes in the fly-ash based geopolymers [32,39-42], the whole reaction process is accompanied by changes in the ion concentration.

The first step is dissolution, in which the glassy components of the fly ash are dissolved in the pore solution. In strongly alkaline solutions, $\mathrm{Al}-\mathrm{O}-\mathrm{Al}, \mathrm{Si}-\mathrm{O}-\mathrm{Si}$ bonds are broken and silicate monomers ( $\mathrm{Si}-\mathrm{OH}$ group) and aluminum monomers (Al-OH group) start to form [32]. The dissolution rate is strongly correlated to the alkali content and to the $\mathrm{pH}$ of the reaction solutions [8]. The associated equations of the dissolution step in strongly alkaline solution for the studied systems are as follows:

$$
\begin{aligned}
& \left(\mathrm{SiO}_{2}\right)_{\text {amorph }}+\mathrm{H}_{2} \mathrm{O}+\mathrm{OH}^{-}=\mathrm{SiO}(\mathrm{OH})_{3}^{-} \\
& \left(\mathrm{Al}_{2} \mathrm{O}_{3}\right)_{\mathrm{amorph}}+3 \mathrm{H}_{2} \mathrm{O}+2 \mathrm{OH}^{-}=2 \mathrm{Al}(\mathrm{OH})_{4}^{-}
\end{aligned}
$$

The silicate and aluminate monomers are dispersed in the solution after the dissolution step. Due to the large amount of free ions in the alkali activator with high $\mathrm{pH}$ during this period, the initial $\mathrm{RH}$ value was relatively low, as shown in Section 3.1. The measured RH of the alkali activator was similar to the initial $\mathrm{RH}$ of the system.

The second step is the oligomerization of silicate and aluminate monomers [40-42], as seen in Eq.(5a) and Eq.(5b): 


$$
\begin{aligned}
& k \mathrm{SiO}(\mathrm{OH})_{3}^{-}=\left[\mathrm{Si}_{k} \mathrm{O}_{l}(\mathrm{OH})_{3 k-2 l}\right]^{-}+l \mathrm{H}_{2} \mathrm{O} \\
& m \mathrm{Al}(\mathrm{OH})_{4}^{-}=\left[\mathrm{Al}_{m} \mathrm{O}_{p}(\mathrm{OH})_{4 m-2 p}\right]^{-}+p \mathrm{H}_{2} \mathrm{O}
\end{aligned}
$$

in which, the coefficients $k, l, m$ and $p$ are depending on the original compositions of the fly ash and the alkali activators and reaction conditions [40].

The next two steps are associated with the polymerization process, in which three-dimensional aluminosilicate gels are formed:

1) the deprotonation equilibrium controls the distribution of silica species, forming a so-called "geopolymer precursor" [42]. Alkali ions, $\mathrm{Na}^{+}$or $\mathrm{K}^{+}$, are incorporated into the structure, compensating the negative charges of the aluminosilicate structures [41]. Taking the alkali activator $\mathrm{NaOH}$ as an example, the associated equation is:

$$
\begin{aligned}
& {\left[\mathrm{Al}_{m} \mathrm{O}_{p}(\mathrm{OH})_{4 m-2 p}\right]^{-}+\left[\mathrm{Si}_{k} \mathrm{O}_{l}(\mathrm{OH})_{3 k-2 l}\right]^{-}+q \mathrm{OH}^{-}+q \mathrm{Na}^{+}} \\
& =\left[\mathrm{Si}_{k} \mathrm{Al}_{m} \mathrm{O}_{l+m+p+q}(\mathrm{OH})_{3 k+4 m-2 p-2 l-q}\right]^{q-} \cdot q \mathrm{Na}^{+}+q \mathrm{H}_{2} \mathrm{O}
\end{aligned}
$$

2) the polycondensation is a step connecting all geopolymer precursors together to form a 3D network:

$$
\begin{aligned}
& n\left(\left[\mathrm{Si}_{k} \mathrm{Al}_{m} \mathrm{O}_{l+m+p+q}(\mathrm{OH})_{3 k+4 m-2 p-2 l-q}\right]^{q-} \cdot q \mathrm{Na}^{+}\right) \\
& \quad=\left[\mathrm{Si}_{n k} \mathrm{Al}_{n m} \mathrm{O}_{n(l+m+p+q)}(\mathrm{OH})_{n(3 k+4 m-2 p-2 l-q)-2 w}\right]^{n q-} \cdot n q \mathrm{Na}^{+}+w \mathrm{H}_{2} \mathrm{O}
\end{aligned}
$$

During the polymerization step, small molecules are connected to larger molecules with different elements embedded in the structure, forming a gel with short range structure $[8,43]$. When using alkali silicate solution in the activator, soluble $\mathrm{SiO}_{2}$ can also be introduced into the $3 \mathrm{D}$ network during polymerization. Note that in the reaction of the alkali-activated materials, the abovementioned steps are occurring in parallel [40]. Along with the abovementioned reaction equations, the ions in the solution, such as $\mathrm{Na}^{+}$, $\mathrm{SiO}_{4}{ }^{2-}, \mathrm{Al}^{3+}, \mathrm{K}^{+}, \mathrm{Ca}^{2+}, \mathrm{Mg}^{2+}$ and $\mathrm{OH}^{-}$are combined into the reaction products. As the total ion concentration of the solution evolves, so does the RH of the solution. According to Eq.(6) and Eq.(7), the $\mathrm{Na}, \mathrm{Si}$ and $\mathrm{OH}^{-}$were incorporated into the aluminosilicate gel. The uptake of these three species in the aluminosilicate gel had significant effects on the RH change (Fig.1).

\subsection{Degree of reaction and associated reaction models}

Figure 6 shows the reaction degree of FA-NS and FA-NH at $20{ }^{\circ} \mathrm{C}$ and $40{ }^{\circ} \mathrm{C}$ quantified with selective dissolution. FA-NS and FA-NH at $20{ }^{\circ} \mathrm{C}$ reached a reaction degree of about 0.17 and the increase was relatively small up to 14 days. At higher temperature, the increase of the reaction degree in FA-NS was stable and the system reached a reaction degree of about 0.36 at 14 days. The increase of the RH in FANS at $20{ }^{\circ} \mathrm{C}$ from 3 days to 14 days was also minor compared to the one at $40{ }^{\circ} \mathrm{C}$, which was reasonable considering the almost constant reaction degree (Fig.6). At $40{ }^{\circ} \mathrm{C}$, the degree of reaction of fly ash in FA$\mathrm{NH}$ reached a higher value than for FA-NS after 3 days. A similar difference between the reaction degree and the reaction kinetics was also observed in the RH change, see Fig.1. 


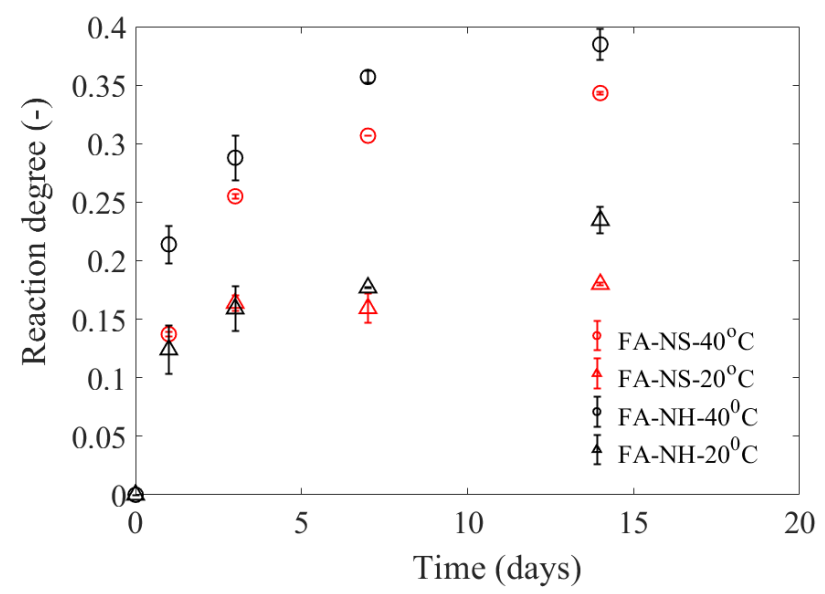

Figure 6. Reaction of fly ash in geopolymers using selective dissolution.

The reaction of geopolymers is generally modeled using a modified Jander equation, which describes the phase boundary reaction and diffusion through a reactant layer [44,45], see Fig.7. Compared to the Avrami equation, the modified Jander equation gives a better fit for fast diffusion systems, e.g. geopolymers in highly alkaline environment [44]. The application of the Jander equation in cementitious materials has been controversial because its derivation is based on neglecting the particle surface curvature during the reaction. Provis reexamined the validity of the Jander equation in [46] and found that no significant errors were introduced when applying the model in systems with low extents of reaction (degree of reaction lower than 0.25-0.3). In the current study, the maximum reaction of fly ash at different temperature was about 0.35 . It is therefore expected that using more complex models (e.g., GinstlingBrounshtein [47] ) would not affect the results substantially.

The general form of the modified Jander model by Kondo et al. [48] is as follows:

$$
\left[1-\left(1-R_{f}\right)^{1 / 3}\right]^{N}=k \cdot t
$$

in which, $k$ is the rate constant, $t[\mathrm{~h}]$ is the reaction time, $N$ represents the rate controlling mechanisms, e.g. for $N=1$, the reaction rate is controlled by boundary kinetics; for $N>1$, the reaction is controlled by diffusion. For $N<2$, the diffusion of the reactants is through a loose layer; for $N>2$, the reaction rate is controlled by diffusion of reactants through a dense layer $[45,48]$.

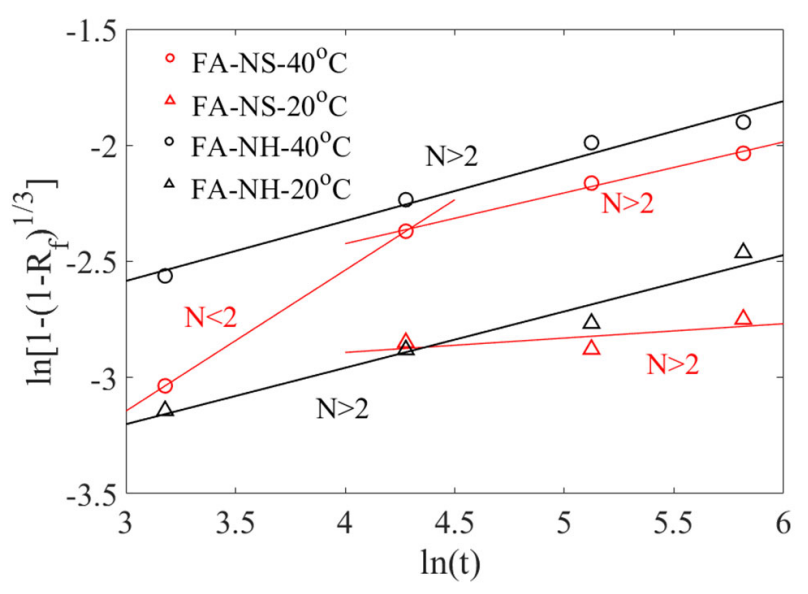


Figure 7. Reaction kinetic analysis of the geopolymerization process with a kinetics model using the measured degree of reaction as input.

\subsection{Assessment of the method using RH evolution for reaction kinetics}

The cumulative heat curve and the RH evolution show generally a similar trend, see Section 3. In addition, to confirm the feasibility of using the RH evolution to measure the reaction kinetics in fly-ash based geopolymers, a) the heat flux was compared to the rate of $\mathrm{RH}$ change and b) the apparent activation energy was calculated both based on the cumulative heat release and on the RH change.

Comparison between the kinetics of reaction heat and $R H$

The heat flux and the RH kinetics are plotted together for FA-NS and FA-NH from $0.1 \mathrm{~d}$ to $5.5 \mathrm{~d}$ at $20^{\circ} \mathrm{C}$ in Fig.8 (a) and (b). The RH value collected every 10 min was used to calculate the kinetics and the first derivative was smoothed using a Savitzky-Golay smoothing filter with point of window 100 and order of polynomial 2 [49]. In both fly-ash based geopolymers, the kinetics of the heat release and of the internal $\mathrm{RH}$ were almost identical, including the small peak appearing at about $0.5 \mathrm{~d}$ in FA-NH.

(a)

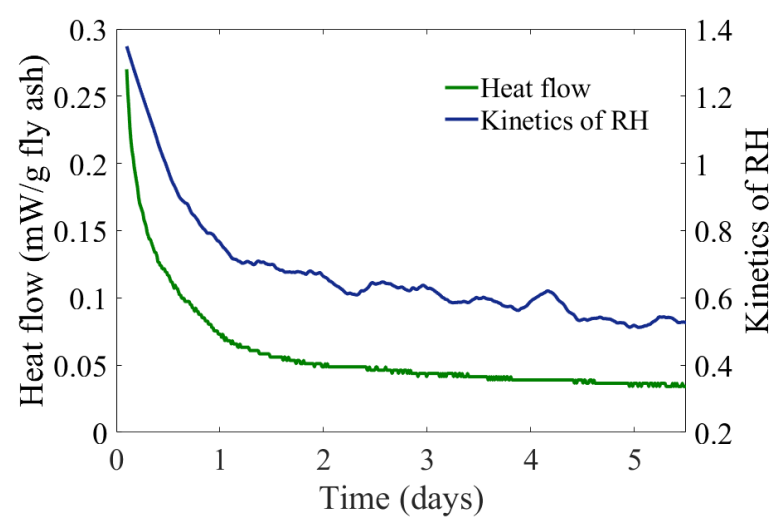

(c)

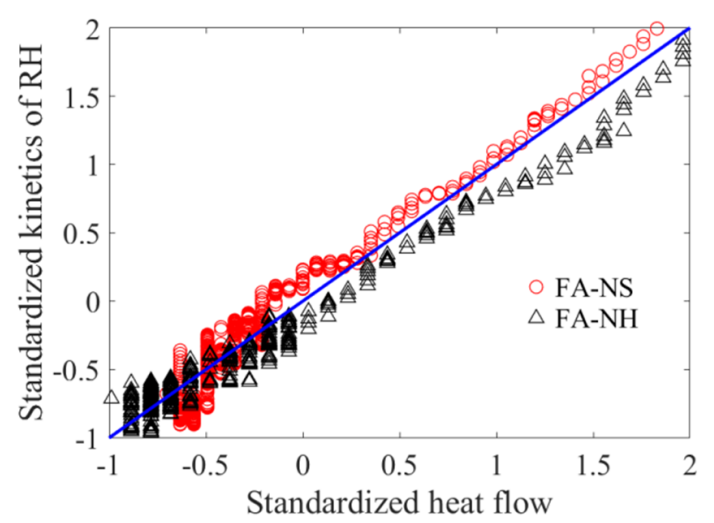

(b)

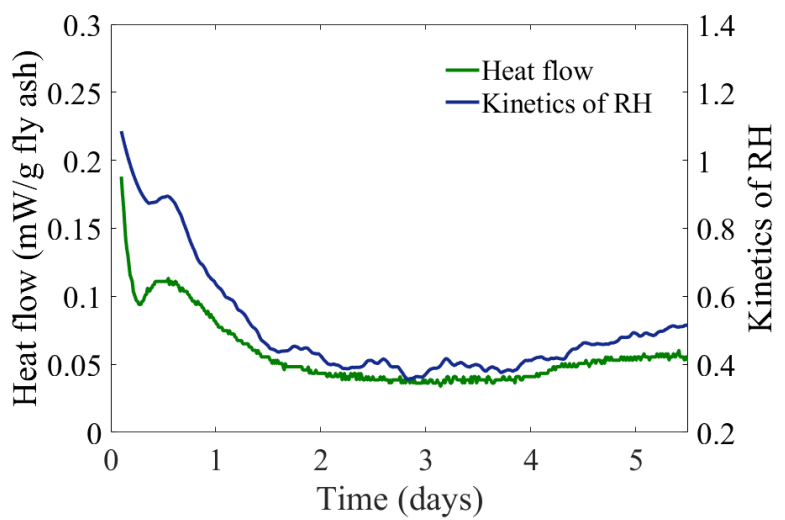

Figure 8. Comparison of the kinetics of heat release and RH in FA-NS (a) and in FA-NH (b) at $20{ }^{\circ} \mathrm{C}$ and correlation between standardized heat flow and standardized kinetics of RH (c)(the results shown in the figure (c) ranged from $0.5 \mathrm{~d}$ to $5 \mathrm{~d}$ ). 
To quantitatively determine the degree of correlation between the heat flux and the RH kinetics, the correlation coefficient was calculated in both systems. Both the heat flux and the RH kinetics were standardized by subtracting the average value from the raw results and then dividing by the standard deviation. A high correlation coefficient (about 0.95) was found for both systems. Fig.8(c) shows the standardized heat flux curve against the standardized RH kinetics. The slope of the curves for both systems is close to 1 (the blue line in Fig.8 (c) has slope 1), highlighting the good correlation between the two kinetics.

\section{Apparent activation energy}

The apparent activation energy is a widely used parameter to define the temperature dependency of a reacting system [50]. Different values of the apparent activation energy refer to the different energy needed for a material to start the reaction. In geopolymers, not only the nature of the solid material but also the used alkali activators affects this value $[51,52]$.

A single, fixed activation energy was calculated for a reacting system in most of the literature, e.g. for Portland cement systems or for geopolymers. The commonly used methods are the linear approximation method [53] and the modified ASTM C 1074-17 standard method [7,54]. Both methods calculate the apparent activation energy based on the Arrhenius equation, as follows:

$$
k_{t}=A \cdot \exp \left(\frac{-E_{a}}{R T}\right)
$$

in which, $E_{a}$ is the apparent activation energy $[\mathrm{kJ} / \mathrm{mol}], k_{t}$ is the reaction rate $\left[\right.$ day $\left.^{-1}\right], R$ is the universal gas constant, equal to $8.314 \cdot 10^{-3} \mathrm{~kJ} / \mathrm{mol} / \mathrm{K}, T$ is the temperature $[\mathrm{K}], A$ is the constant [day ${ }^{-1}$ ]. The activation energy can be estimated from the slope of the plot of $\ln k_{t}$ and $1 / T$. The reaction rate is then found either from the linear approximation from the heat evolution curve or with the maturity concept from the asymptotic model of a property (e.g., compressive strength [54]). The model for the compressive strength is usually formulated as:

$$
P_{t}=P_{\infty} \cdot \frac{k_{t}\left(t-t_{0}\right)}{1+k_{t} \cdot\left(t-t_{0}\right)}
$$

in which, $P_{t}$ and $P_{\infty}\left[\mathrm{MPa}\right.$ ] are the compressive strength at time $t$ [day] and at infinite time, $t_{0}$ [day] is the setting time.

However, since the reactions that occur in the system are triggered by different phases, which react at different ages and with different rates, the apparent activation energy is expected to vary with the degree of reaction, as shown in [51,55]. The method used in the current study was based on the concept of 'equivalent age' $\left(t_{\mathrm{e}}\right)$ using the results from the three temperatures $\left(20^{\circ} \mathrm{C}, 30^{\circ} \mathrm{C}\right.$ and $\left.40{ }^{\circ} \mathrm{C}\right)$ [56]. The equation to compute the $t_{e}$ is as follows:

$$
t_{e}\left(T_{r}\right)=\sum_{0}^{t} e^{-\frac{E a}{R}\left(\frac{1}{T_{c}}-\frac{1}{T_{r}}\right)} \cdot \Delta t
$$

in which, $T_{r}$ and $T_{c}$ are the reference temperature $[\mathrm{K}]$ and current material temperature $[\mathrm{K}]$. To determine $E_{a}$, the relationship between $\ln \left(t_{e}\right)$ and $1 / T$ is required. From the heat release results of each system at the three temperatures, the three equivalent ages $\left(t_{e}\right)$ were recorded for different heat release values (with interval of $0.2 \mathrm{~J} / \mathrm{g}) \cdot \ln \left(t_{e}\right)$ and $1 / T$ were plotted and fitted with a line. Then, based on Eq.(10), the $E_{a}$ can be 
calculated with the slope of the fitted line. Two types of calculations were performed in this study, based respectively on: 1) cumulative heat release from isothermal calorimetry and 2) relative humidity change from water activity sensors. The calculated $E_{a}$ from the abovementioned two methods is shown as a function of cumulative heat release and relative humidity change in Fig.9. Approximately similar apparent activation energy in FA-NH and FA-NS was obtained at the same cumulative heat while higher apparent activation energy in FA-NH was obtained at the same RH change.

(a)

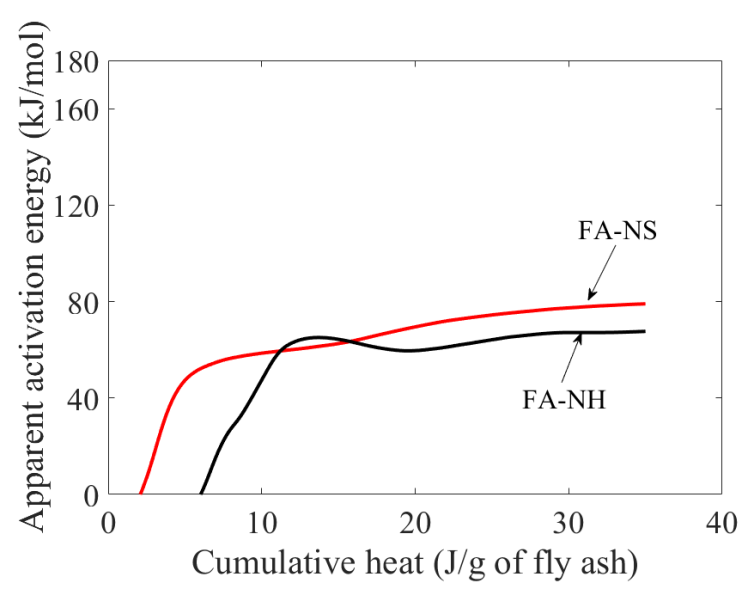

(b)

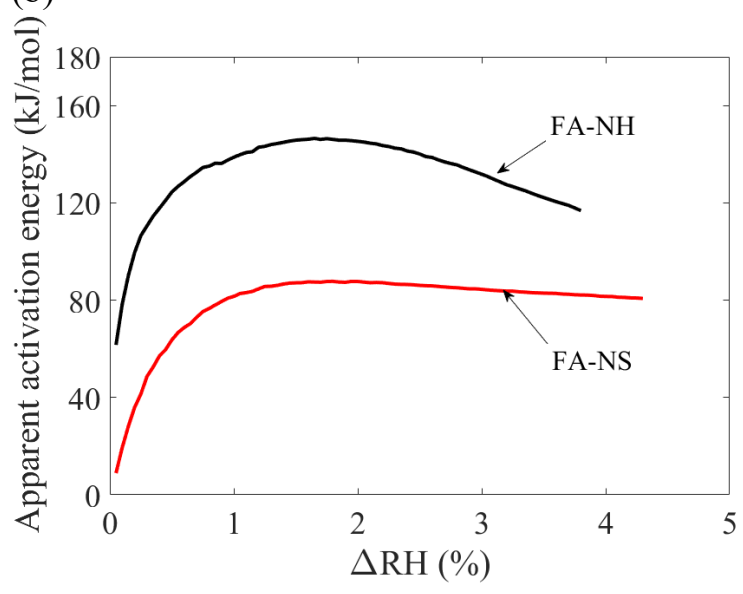

Figure 9. Calculated apparent activation energy from cumulative heat release and from internal RH change as a function of cumulative heat and RH change: (a) from cumulative heat release; (b) from internal RH change.

To better show the results of both methods, the obtained $E_{a}$ was also plotted as a function of the degree of reaction. The degree of reaction was estimated using the measured degree of reaction (Fig.6) in the previous section. The apparent activation as a function of estimated degree of reaction is shown in Fig.10. The $E_{a}$ increased from a low value and started to decrease at degree of reaction of about 0.05 until reaching a stable value. While higher $E_{a}$ was obtained with the internal $\mathrm{RH}$ than with the cumulative heat release at degree of reaction $<0.1$, the values were comparable afterwards. Similar stable $E_{a}$ of FA-NS was observed from both methods. Calculated from RH change, the stable $E_{a}$ of FA-NS was lower than that of FA-NH, indicating a higher energy barrier for further reaction between fly ash and NH. A similar observation was reported in the literature: when activated with 8 to $10 \mathrm{M} \mathrm{NaOH}$, the activation energy was in the range of $80-86 \mathrm{~kJ} / \mathrm{mol}[7,52,57]$. The higher the concentration of $\mathrm{NaOH}$, the higher the activation energy: e.g., $50 \mathrm{~kJ} / \mathrm{mol}$ was measured for systems activated with $6 \mathrm{M} \mathrm{NaOH} \mathrm{[52].} \mathrm{When} \mathrm{activated} \mathrm{with}$ waterglass solution, the activation energy was much lower, e.g. $24 \mathrm{~kJ} / \mathrm{mol}$ in systems activated with $\mathrm{NaOH}$, waterglass and sodium polyacrylate solution [58]. Similar trends were found in the present study, particularly in the calculation based on RH: about $120 \mathrm{~kJ} / \mathrm{mol}$ for FA-NH and about $80 \mathrm{~kJ} / \mathrm{mol}$ for FA-NS. Note that the differences between both the fly ash type and the composition of the alkali activation solutions used in the current work and in the literature, will have a large impact on the $E_{a}$. 

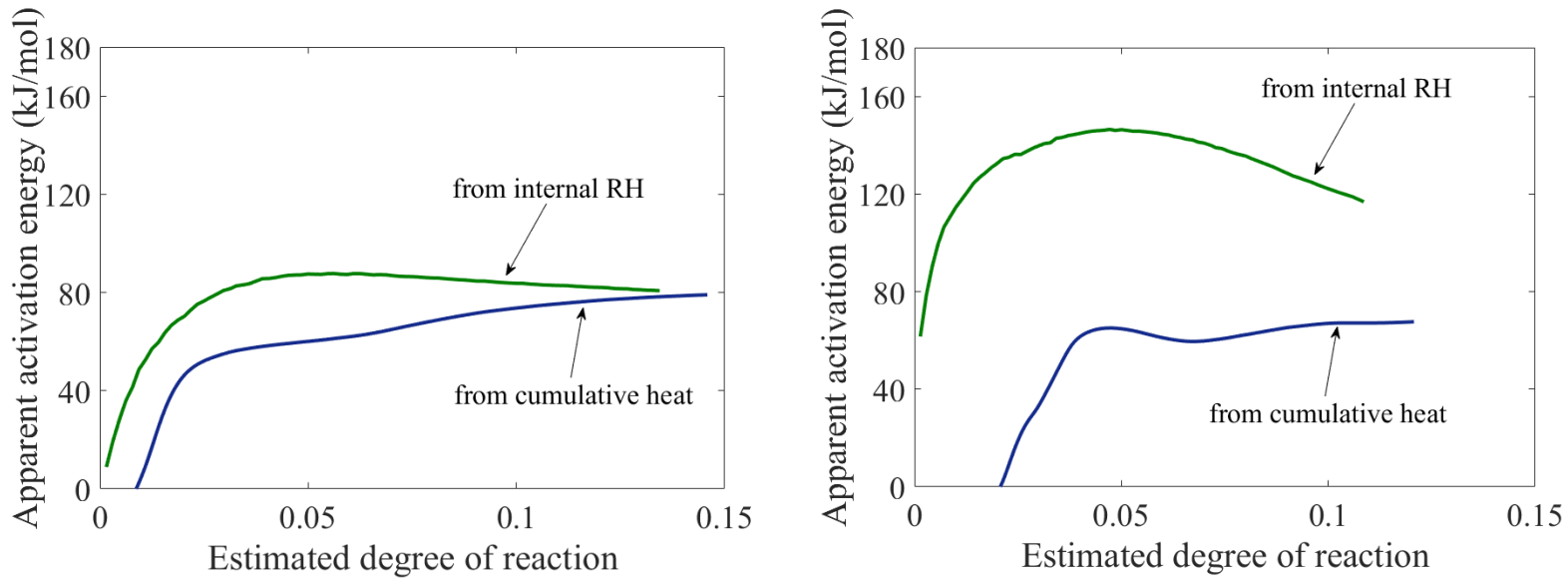

Figure 10. Calculated apparent activation energy from cumulative heat release and from internal RH change as a function of degree of reaction: (a) for FA-NS; (b) for FA-NH.

\subsection{Advantages and limitations of the new method}

This paper presents a novel method to follow the reaction kinetics of fly-ash based geopolymers based on measurements of the internal RH. The RH measurement is easier to conduct and benefits of having higher accuracy at longer hydration time compared to isothermal calorimetry, thanks to its higher signal-to-noise ratio and the recoverability of the measurements after any disturbance. A small amount of reaction, which may not generate a high enough signal in the rate of heat liberation, can still be evident from the corresponding internal $\mathrm{RH}$ change caused by the change in pore solution composition. Contrary to calorimetry, the internal $\mathrm{RH}$ can also be measured at discrete time points, potentially also on different samples. Only a small amount of material is needed and it does not have strict limitations in the temperature range (theoretically, the operating temperature of the water activity sensors used in this study is $5-65^{\circ} \mathrm{C}$ ).

The principle of the method presented in this paper is the dependence of the RH change on the change of ions present in the pore solution. It is assumed that the ions in pore solution are in constant equilibrium with the solids and hence the change in the pore solution concentration can occur only due to the corresponding exchange of ions with the solids. Consequently, by following the changes of RH we can follow the evolution of the solids. A further assumption is that the equilibrium RH measured dynamically on the system corresponds to the water activity of the pore solution. It should be stressed that the internal RH measurements on pastes are at best equivalent to a measurement of water activity of the pore solution, from which the composition of the pore solution cannot be unambiguously calculated. The method proposed in this paper is similar to measurements of conductivity to follow the reaction in diluted cementitious systems $[59,60]$. One advantage compared to measurements of conductivity is that the $\mathrm{RH}$ measurement itself is simpler and can be performed on the actual system of interest (it does not require a diluted system). As is true also of conductivity measurements, it is possible to extract quantitative results about the degree of reaction when additional information on the composition of pore solution is available. Fig.5 shows preliminary results in that direction, which show that the activity of the extracted pore solution calculated with GEM-Selektor is close to the RH measured on pastes. Another direct use of the measured RH to provide quantitative predictions is shown in the calculation of the apparent activation energy (section 4.4). 
This novel method is particularly apt for geopolymers that have limited self-desiccation due to the nature of their chemical reactions, such as fly ash- and metakaolin-based geopolymers. The magnitude of the self-desiccation depends on the composition of the raw material and the mixture design. If self-desiccation is limited, the RH evolution is primarily driven by the composition changes in the pore solution. Note that this estimation is also limited to a certain degree of reaction even though the reaction in fly ash and metakaolin based geopolymers does not consume free water but rather physically adsorbs free water. In alkali-activated systems with reaction products of C-A(N)-S-H (e.g. using slag), the evolution of internal RH likely comes from a combination of both changes in the pore solution (which will be prevalent initially) and of self-desiccation (which may occur only after solidification of the material). Higher chemical shrinkage was observed with alkali-activated systems with higher amount of slag [61]. In this case, to obtain the reaction kinetics, the corresponding RH due to the pore solution change could theoretically be calculated with the help of direct capillary pressure measurements. However, this approach is not as straightforward and can be applied only in case of limited self-desiccation, due to the small range of capillary pressure that can be measured with tensiometers $[62,63]$.

\section{Conclusions}

This study focused on the internal RH of fly-ash based geopolymers activated either with a solution of waterglass and $\mathrm{NaOH}$ or solely with $\mathrm{NaOH}$ at 20,30 and $40{ }^{\circ} \mathrm{C}$. An increase of $\mathrm{RH}$ was observed in the studied systems, starting from a low RH value. The RH evolution in fly-ash based geopolymers was explained for the first time based on evidence gathered from a number of supporting experiments. The initial RH was mainly related to the ionic strength of the activator solution. The evolution of the internal RH of the fly-ash based geopolymers was used as a convenient method for following the reaction kinetics. In this study, both the theory behind the method and the reaction process has been analyzed. The following conclusions can be drawn:

1. The low initial $\mathrm{RH}$ and the $\mathrm{RH}$ evolution are mainly due to ions present originally in the alkali activator, with only limited contribution from the ions dissolved from the fly ash. This can be easily explained by the different magnitude of the amount of ions from the alkali activators and from the dissolution of the fly ash;

2. Different steps during the reaction process are reflected in the RH evolution. The RH method shows a similar evolution as the cumulative heat from isothermal calorimetry, but with higher signal to noise ratio, especially for systems prepared with low-reactivity reactants;

3. When the activator solution contained waterglass, at higher temperature the reaction is mainly diffusion-controlled; along the reaction time, it changes from diffusion-controlled through a loose layer to through a dense layer. When the activator solution is solely $\mathrm{NaOH}$ solution, the reaction rate is controlled by diffusion through a dense layer at different temperatures;

4. The kinetics of heat release and $\mathrm{RH}$ evolution show a high degree of correlation, with correlation coefficient 0.95 in both geopolymers at $20^{\circ} \mathrm{C}$. The calculated activation energies based on cumulative heat release and on the evolution of internal RH agree well. Based on RH change, about $80 \mathrm{~kJ} / \mathrm{mol}$ and $120 \mathrm{~kJ} / \mathrm{mol}$ were calculated when using an activator solution of mixed waterglass and $\mathrm{NaOH}$ and of solely $\mathrm{NaOH}$, respectively;

5. The novel method based on RH measurements is applicable to fly-ash based geopolymers with the reaction degree of the fly ash lower than about 0.35 . When using this method for quantifying the reaction kinetics of other materials, possible self-desiccation needs to be taken into consideration. 


\section{Acknowledgement}

The authors would like to thank Luigi Brunetti, Bin Ma and Yiru Yan for pore solution extraction and IC measurements. Frank Winnefeld is acknowledged for providing the XRF and XRD results of the raw fly ash, for the inspiring discussion on determination of degree of reaction of fly ash with selective dissolution method and for critical review of the manuscript. The authors thank Barbara Lothenbach for helping with the thermodynamic modelling with GEM-Selector software.

\section{Appendix A}

The RH evolution of the alkali activators as a function of time is shown in Fig.A. As seen in the figure, the equilibrium between the sensor and specimens of RH change at early ages is reached in relatively short time, after about 1 hour at both temperatures. Therefore, the impact of the exclusion of the moisture equilibrium in the system is considered not to be significant. However, the variation of the RH before equilibrium at higher temperature is surely higher than that at lower temperature.

(a)

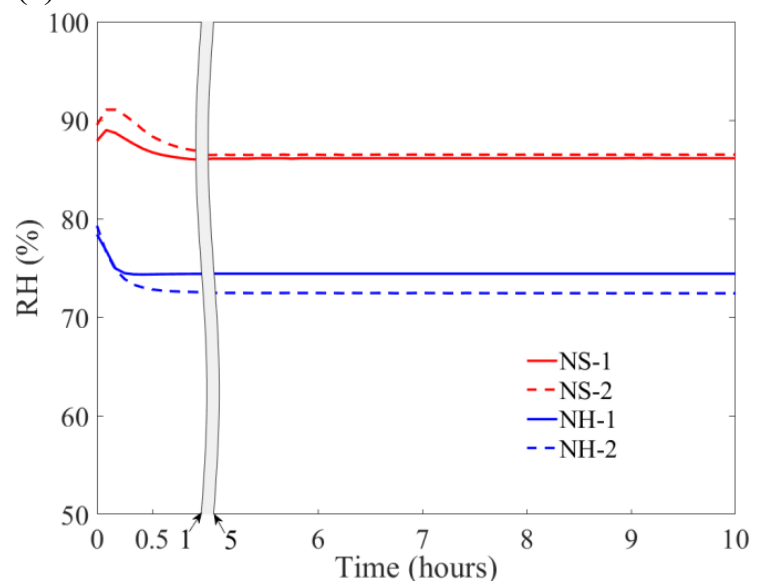

(b)

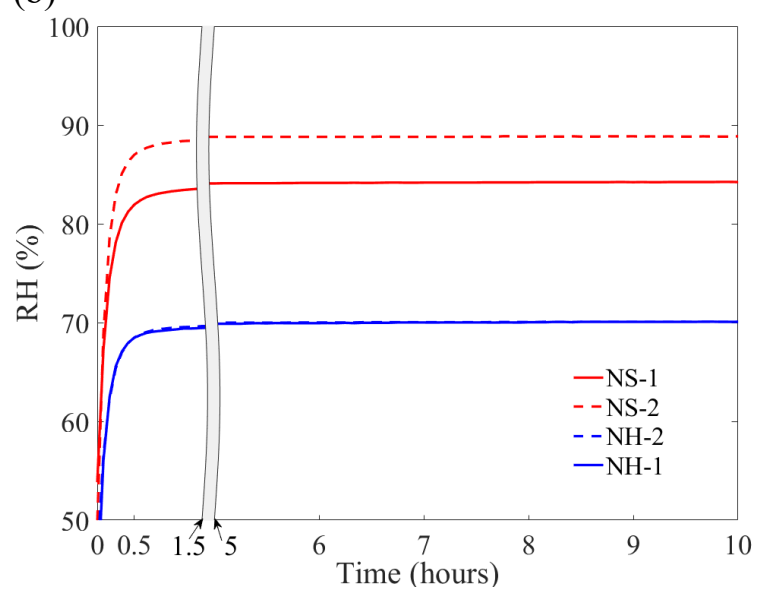

Figure A. Evolution of RH of alkali activators (NH and NS) at two temperatures: (a) at $20^{\circ} \mathrm{C}$; (b) at $40{ }^{\circ} \mathrm{C}$.

\section{References}

[1] A. Palomo, M. Grutzeck, M. Blanco, Alkali-activated fly ashes: a cement for the future, Cem. Concr. Res. 29(8): (1999) 1323-1329.

[2] F. Puertas, S. Martínez-Ramírez, S. Alonso, T. Vázquez, Alkali-activated fly ash/slag cements, Cem. Concr. Res. 30 (2002) 1625-1632.

[3] G. Habert, J.B. D’Espinose De Lacaillerie, N. Roussel, An environmental evaluation of geopolymer based concrete production: Reviewing current research trends, J. Clean. Prod. 19 (2011) 1229-1238.

[4] S. Alberici, J. De Beer, I. Van Der Hoorn, M. Staats, Fly ash and blast furnace slag for cement manufacturing: BEIS research paper no. 19, 2017.

[5] J. Davidovits, Geopolymers: Inorganic polymeric new materials, J. Therm. Anal. 37 (1991) $1633-$ 1656. 
[6] K.L. Scrivener, B. Lothenbach, N. De Belie, E. Gruyaert, J. Skibsted, R. Snellings, A. Vollpracht, TC 238-SCM: hydration and microstructure of concrete with SCMs, Mater. Struct. (2015) 835-862.

[7] Z. Sun, A. Vollpracht, Isothermal calorimetry and in-situ XRD study of the $\mathrm{NaOH}$ activated fly ash, metakaolin and slag, Cem. Concr. Res. 103 (2018) 110-122.

[8] A. Fernández-Jiménez, A. Palomo, M. Criado, Microstructure development of alkali-activated fly ash cement: A descriptive model, Cem. Concr. Res. 35 (2005) 1204-1209.

[9] S. Songpiriyakij, T. Kubprasit, C. Jaturapitakkul, P. Chindaprasirt, Compressive strength and degree of reaction of biomass- and fly ash-based geopolymer, Constr. Build. Mater. 24 (2010) 236-240.

[10] M.L. Granizo, S. Alonso, M.T. Blanco-Varela, A. Palomo, Alkaline activation of metakaolin: effect of calcium hydroxide in the products of reaction, J. Am. Ceram. Soc. 85 (2010) 225-231.

[11] N.K. Lee, H.K. Lee, Reactivity and reaction products of alkali-activated, fly ash/slag paste, Constr. Build. Mater. 81 (2015) 303-312.

[12] D. Tse, S. Hartmann, Nuclear spin-lattice relaxation via paramagnetic centers without spin diffusion, Phys. Rev. Lett. 21 (1968) 511-514.

[13] J.L. Provis, J.S.J. van Deventer, Geopolymerisation kinetics. 1. In situ energy-dispersive X-ray diffractometry, Chem. Eng. Sci. 62 (2007) 2309-2317.

[14] J.L. Provis, J.S.J. van Deventer, Geopolymerisation kinetics. 2. Reaction kinetic modelling, Chem. Eng. Sci. 62 (2007) 2318-2329.

[15] P. Lura, O.M. Jensen, K. van Breugel, Autogenous shrinkage in high-performance cement paste: An evaluation of basic mechanisms, Cem. Concr. Res. 33 (2003) 223-232.

[16] G. Fang, H. Bahrami, M. Zhang, Mechanisms of autogenous shrinkage of alkali-activated fly ashslag pastes cured at ambient temperature within 24 h, Constr. Build. Mater. 171 (2018) 377-387.

[17] Y. Ma, G. Ye, The shrinkage of alkali activated fly ash, Cem. Concr. Res. 68 (2015) 75-82.

[18] L. Greenspan, Humidity fixed points of binary saturated aqueous solutions, J Res Natl Bur Stand Sect A Phys Chem. 81 A (1977) 89-96.

[19] L. Wadsö, Applications of an eight-channel isothermal conduction calorim- eter for cement hydration studies, Cem. Int. 5 (2002) 94-101.

[20] B. Lothenbach, G. Le Saout, E. Gallucci, K. Scrivener, Influence of limestone on the hydration of Portland cements, Cem. Concr. Res. 38 (2008) 848-860.

[21] B. Lothenbach, Thermodynamic equilibrium calculations in cementitious systems, Mater. Struct. Constr. 43 (2010) 1413-1433.

[22] T. Wagner, D.A. Kulik, F.F. Hingerl, S. V. Dmytrievava, Gem-selektor geochemical modeling package: TSolMod library and data interface for multicomponent phase models, Can. Mineral. 50 (2012) 1173-1195. doi:10.3749/canmin.50.5.1173.

[23] D.A. Kulik, T. Wagner, S. V Dmytrieva, G. Kosakowski, F.F. Hingerl, K. V Chudnenko, U.R. Berner, GEM-Selektor geochemical modeling package: Revised algorithm and GEMS3K numerical kernel for coupled simulation codes, Comput. Geosci. 17 (2013) 1-24. doi:10.1007/s10596-012-9310-6.

[24] B. Lothenbach, D.A. Kulik, T. Matschei, M. Balonis, L. Baquerizo, B. Dilnesa, G.D. Miron, R.J. Myers, Cemdata18: A chemical thermodynamic database for hydrated Portland cements and alkaliactivated materials, Cem. Concr. Res. 115 (2019) 472-506. doi:10.1016/j.cemconres.2018.04.018.

[25] R.J. Myers, S.A. Bernal, J.L. Provis, A thermodynamic model for C-(N-)A-S-H gel: CNASH-ss. 
Derivation and validation, Cem. Concr. Res. 66 (2014) 27-47.

doi:10.1016/j.cemconres.2014.07.005.

[26] H.C. Helgeson, D.H. Kirkham, G.C. Flowers, Theoretical prediction of the thermodynamic behavior of aqueous electrolytes at high pressures and temperatures: IV. Calculation of activity coefficients, osmotic coefficients, and apparent molal and standard and relative partial molal properties to $600^{\circ} \mathrm{C}$, Am. J. Sci. 281 (1981) 1249-1516.

[27] Z. Hu, M. Wyrzykowski, K. Scrivener, P. Lura, A novel method to predict internal relative humidity in cementitious materials by 1 H NMR, Cem. Concr. Res. 104 (2018) 80-93.

[28] J. Justs, M. Wyrzykowski, D. Bajare, P. Lura, Internal curing by superabsorbent polymers in ultrahigh performance concrete, Cem. Concr. Res. 76 (2015) 82-90.

[29] C. Shi, P. V Krivenko, D. Roy, Alkali-activated cements and concretes, CRC Press, 2010.

[30] S. Chithiraputhiran, N. Neithalath, Isothermal reaction kinetics and temperature dependence of alkali activation of slag, fly ash and their blends, Constr. Build. Mater. 45 (2013) 233-242.

[31] Y. Zuo, M. Nedeljković, G. Ye, Pore solution composition of alkali-activated slag/fly ash pastes, Cem. Concr. Res. 115 (2019) 230-250.

[32] A. Fernández-Jiménez, A. Palomo, Composition and microstructure of alkali activated fly ash binder: Effect of the activator, Cem. Concr. Res. 35 (2005) 1984-1992.

[33] M. Criado, A. Fernández-Jiménez, A. Palomo, Alkali activation of fly ash: Effect of the SiO2/Na2O ratio Part I: FTIR study, Microporous Mesoporous Mater. 106 (2007) 180-191.

[34] H. Chen, M. Wyrzykowski, K. Scrivener, P. Lura, Prediction of self-desiccation in low water-tocement ratio pastes based on pore structure evolution, Cem. Concr. Res. 49 (2013) 38-47.

[35] P. Lura, B. Lothenbach, Influence of pore solution chemistry on shrinkage of cement paste, 50Year Teach. Res. Anniv. Prof. Sun Wei Adv. Civ. Eng. Mater. (2010) 191-200.

[36] T. Yang, H. Zhu, Z. Zhang, Influence of fly ash on the pore structure and shrinkage characteristics of metakaolin-based geopolymer pastes and mortars, Constr. Build. Mater. 153 (2017) 284-293.

[37] C. Kuenzel, L.J. Vandeperre, S. Donatello, A.R. Boccaccini, C. Cheeseman, Ambient temperature drying shrinkage and cracking in metakaolin-based geopolymers, J. Am. Ceram. Soc. 95 (2012) $3270-3277$.

[38] Y. Ma, Microstructure and Engineering Properties of Alkali Activated Fly Ash - as an environment friendly alternative to Portland cement, TU Delft, 2013.

[39] N. Murayama, H. Yamamoto, J. Shibata, Mechanism of zeolite synthesis from coal fly ash by alkali hydrothermal reaction, Int. J. Miner. Process. 64 (2002) 1-17.

[40] D. Dimas, I. Giannopoulou, D. Panias, Polymerization in sodium silicate solutions: A fundamental process in geopolymerization technology, J. Mater. Sci. 44 (2009) 3719-3730.

[41] J. Davidovits, Geopolymer chemistry and sustainable development.The Poly(sialate) terminology: a very useful and simple model for the promot ion and understanding of green-chemistry., in: Geopolymer Green Chem. Sustain. Dev. Solut., 2005.

[42] J. Šefčík, A. V. McCormick, Thermochemistry of aqueous silicate solution precursors to ceramics, AIChE J. 43 (2004) 2773-2784.

[43] A.S. De Vargas, D.C.C. Dal Molin, A.C.F. Vilela, F.J. Da Silva, B. Pavão, H. Veit, The effects of $\mathrm{Na} 2 \mathrm{O} / \mathrm{SiO} 2$ molar ratio, curing temperature and age on compressive strength, morphology and microstructure of alkali-activated fly ash-based geopolymers, Cem. Concr. Compos. 33 (2011) $653-660$. 
[44] D. Ravikumar, N. Neithalath, Reaction kinetics in sodium silicate powder and liquid activated slag binders evaluated using isothermal calorimetry, Thermochim. Acta. 546 (2012) 32-43.

[45] C. Chen, W. Gong, W. Lutze, I.L. Pegg, Kinetics of fly ash geopolymerization, J. Mater. Sci. 46 (2011) 3073-3083.

[46] J.L. Provis, On the use of the Jander equation in cement hydration modelling, RILEM Tech. Lett. 1 (2016) 62.

[47] A.M. Ginstling, B.I. Brounshtein, Concerning the diffusion kinetics of reaction in spherical particles, J. Appl. Chem USSR. 23 (1950) 1327-1338.

[48] R. Kondo, K. Lee, M. Daimon, Kinetics and mechanism of hydrothermal reaction in lime-quartzwater system, J. Ceram. Soc. Japan. 84 (1976) 573-578.

[49] A. Savitzky, M.J.E. Golay, Smoothing and differentiation of data by simplified least squares procedures, Anal. Chem. 36 (1964) 1627-1639.

[50] I. Maruyama, P. Lura, Properties of early-age concrete relevant to cracking in massive concrete, Cem. Concr. Res. 123 (2019) 105770.

[51] S.K. Nath, S. Mukherjee, S. Maitra, S. Kumar, Kinetics study of geopolymerization of fly ash using isothermal conduction calorimetry, J. Therm. Anal. Calorim. 127 (2017) 1953-1961.

[52] S.K. Nath, S. Kumar, Role of alkali concentration on reaction kinetics of fly ash geopolymerization, J. Non. Cryst. Solids. 505 (2019) 241-251.

[53] L.P. Jonathan, A.R. Kyle, J.F. Kevin, C.G.J. Maria, K.S. Anton, Methods for calculating activation energy for Portland cement, ACI Mater. J. 104 (2007) 303.

[54] ASTM C1074-17 Standard practice for estimating concrete strength by the maturity method, (2011) $1-10$.

[55] L. D'Aloia, G. Chanvillard, Determining the "apparent" activation energy of concrete, Cem. Concr. Res. 32 (2002) 1277-1289.

[56] P.F. Hansen, E.J. Pedersen, Maturity computer for controlled curing and hardening of concrete, Nord. Betong. 21 (1977) 19-34.

[57] F. Škvára, L. Kopecký, V. Šmilauer, Z. Bittnar, Material and structural characterization of alkali activated low-calcium brown coal fly ash, J. Hazard. Mater. 168 (2009) 711-720.

[58] M. Romagnoli, P. Sassatelli, M. Lassinantti Gualtieri, G. Tari, Rheological characterization of fly ash-based suspensions, Constr. Build. Mater. 65 (2014) 526-534.

[59] F. Rajabipour, J. Weiss, J.D. Shane, T.O. Mason, S.P. Shah, Procedure to interpret electrical conductivity measurements in cover concrete during rewetting, J. Mater. Civ. Eng. 17 (2005) 586594. doi:10.1061/(ASCE)0899-1561(2005)17:5(586).

[60] F. Rajabipour, J. Weiss, Electrical conductivity of drying cement paste, Mater. Struct. Constr. 40 (2007) 1143-1160. doi:10.1617/s11527-006-9211-z.

[61] N.K. Lee, J.G. Jang, H.K. Lee, Shrinkage characteristics of alkali-activated fly ash/slag paste and mortar at early ages, Cem. Concr. Compos. 53 (2014) 239-248.

[62] C. Miao, Q. Tian, W. Sun, J. Liu, Water consumption of the early-age paste and the determination of "time-zero" of self-desiccation shrinkage, Cem. Concr. Res. 37 (2007) 1496-1501.

[63] S. Ghourchian, M. Wyrzykowski, P. Lura, A poromechanics model for plastic shrinkage of fresh cementitious materials, Cem. Concr. Res. 109 (2018) 120-132. 